Atmos. Chem. Phys., 17, 14955-14974, 2017

https://doi.org/10.5194/acp-17-14955-2017

(C) Author(s) 2017. This work is distributed under

the Creative Commons Attribution 3.0 License.

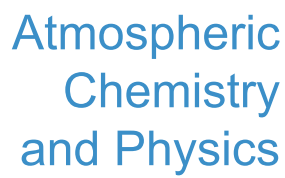

(c) (P)

\title{
Cyclone-induced surface ozone and HDO depletion in the Arctic
}

\author{
Xiaoyi Zhao $^{1, \mathrm{a}}$, Dan Weaver ${ }^{1}$, Kristof Bognar ${ }^{1}$, Gloria Manney ${ }^{2,3}$, Luis Millán $^{4}$, Xin Yang $^{5}$, Edwin Eloranta ${ }^{6}$, \\ Matthias Schneider ${ }^{7}$, and Kimberly Strong ${ }^{1}$ \\ ${ }^{1}$ Department of Physics, University of Toronto, Toronto, Ontario, Canada \\ ${ }^{2}$ NorthWest Research Associates, Socorro, New Mexico, USA \\ ${ }^{3}$ Department of Physics, New Mexico Institute of Mining and Technology, Socorro, New Mexico, USA \\ ${ }^{4}$ Jet Propulsion Laboratory, California Institute of Technology, Pasadena, California, USA \\ ${ }^{5}$ British Antarctic Survey, Natural Environment Research Council, Cambridge, UK \\ ${ }^{6}$ Space Science and Engineering Center, University of Wisconsin, Madison, Wisconsin, USA \\ ${ }^{7}$ Institute of Meteorology and Climate Research (IMK-ASF), Karlsruhe Institute of Technology, Karlsruhe, Germany \\ ${ }^{\mathrm{a}}$ current address: Measurement and Analysis Research Section, Environment and Climate Change Canada, \\ Toronto, Ontario, Canada
}

Correspondence: Xiaoyi Zhao (xizhao@atmosp.physics.utoronto.ca) and

Kimberly Strong (strong@atmosp.physics.utoronto.ca)

Received: 5 May 2017 - Discussion started: 28 June 2017

Revised: 20 October 2017 - Accepted: 2 November 2017 - Published: 19 December 2017

\begin{abstract}
Ground-based, satellite, and reanalysis datasets were used to identify two similar cyclone-induced surface ozone depletion events at Eureka, Canada $\left(80.1^{\circ} \mathrm{N}\right.$, $86.4^{\circ} \mathrm{W}$ ), in March 2007 and April 2011. These two events were coincident with observations of hydrogen deuterium oxide (HDO) depletion, indicating that condensation and sublimation occurred during the transport of the ozonedepleted air masses. Ice clouds (vapour and crystals) and aerosols were detected by lidar and radar when the ozoneand HDO-depleted air masses arrived over Eureka. For the 2007 event, an ice cloud layer was coincident with an aloft ozone depletion layer at $870 \mathrm{~m}$ altitude on 2-3 March, indicating this ice cloud layer contained bromine-enriched blowing-snow particles. Over the following 3 days, a shallow surface ozone depletion event (ODE) was observed at Eureka after the precipitation of bromine-enriched particles onto the local snowpack. A chemistry-climate model (UKCA) and a chemical transport model (pTOMCAT) were used to simulate the surface ozone depletion events. Incorporating the latest surface snow salinity data obtained for the Weddell Sea into the models resulted in improved agreement between the modelled and measured $\mathrm{BrO}$ concentrations above Eureka. MERRA-2 global reanalysis data and the FLEXPART particle dispersion model were used to study the link between the ozone and HDO depletion. In general, the modelled ozone
\end{abstract}

and $\mathrm{BrO}$ showed good agreement with the ground-based observations; however, the modelled $\mathrm{BrO}$ and ozone in the nearsurface layer are quite sensitive to the snow salinity. HDO depletion observed during these two blowing-snow ODEs was found to be weaker than pure Rayleigh fractionation. This work provides evidence of a blowing-snow sublimation process, which is a key step in producing bromine-enriched seasalt aerosol.

\section{Introduction}

Surface ozone depletion events (ODEs) have been observed in the Arctic spring since the 1980s (Bottenheim et al., 1986; Barrie et al., 1988) and have been linked to halogen chemistry (e.g., Simpson et al., 2007; Abbatt et al., 2012). The halogen chemical chain Reactions (R1) to (R4) are usually referred to as "the bromine explosion", to indicate the rapidity of the reaction cycle. The speedup of the cycle is due to the conversion of inactive bromide $\left(\mathrm{Br}^{-}\right)$to gas-phase reac- 
tive bromine (Br), as the net Reaction (R5) shows.

$$
\begin{aligned}
& \mathrm{HOBr}+\mathrm{Br} \text { aq }+\mathrm{H}_{\mathrm{aq}}^{+} \stackrel{\mathrm{mp}}{\longrightarrow} \mathrm{Br}_{2}+\mathrm{H}_{2} \mathrm{O} \\
& \mathrm{Br}_{2} \stackrel{\mathrm{hv}}{\longrightarrow} 2 \mathrm{Br} \\
& \mathrm{Br}+\mathrm{O}_{3} \rightarrow \mathrm{BrO}+\mathrm{O}_{2} \\
& \mathrm{BrO}+\mathrm{HO}_{2} \rightarrow \mathrm{HOBr}+\mathrm{O}_{2} \\
& \mathrm{Net}: \mathrm{Br}+\mathrm{Br}_{\mathrm{aq}}^{-}+\mathrm{H}_{\mathrm{aq}}^{+}+\mathrm{O}_{3}+\mathrm{HO}_{2} \stackrel{\mathrm{mp}, \mathrm{hv}}{\longrightarrow} 2 \mathrm{Br} \\
& \quad+2 \mathrm{O}_{2}+\mathrm{H}_{2} \mathrm{O}
\end{aligned}
$$

Here, subscript "aq" denotes aqueous phase, and mp indicates a multiphase reaction. The activated halogenated species in ODEs can remove gas-phase mercury and deposit the product on snow (Calvert and Lindberg, 2004a, b; Steffen et al., 2008; Toyota et al., 2014; Calvert et al., 2015). The deposited mercury can ultimately reach deep sediments and/or bioaccumulate into wildlife and eventually into humans (Simpson et al., 2007). However, the initial release mechanisms of the reactive bromine into the atmosphere vary. The facilitating meteorological conditions for each ODE may be very different (Abbatt et al., 2012); low winds with a stable shallow boundary layer (Wagner et al., 2001; Frieß et al., 2004; Lehrer et al., 2004) and high winds with an unstable boundary layer (Yang et al., 2008; Jones et al., 2009; Frieß et al., 2011; Blechschmidt et al., 2016; Zhao et al., 2016a) have both been proposed and observed. These different meteorological conditions can lead to different transport pathways for the low-ozone air mass, thereby changing the oxidative capacity of the Arctic troposphere. In blowing snow (wind speed $>12 \mathrm{~m} \mathrm{~s}^{-1}$ ), salty snow aloft can produce sea-salt aerosol (SSA) due to sublimation (Legrand et al., 2016). The bromine-enriched SSA is thought to act as both source and substrate for bromine chemistry (Yang et al., 2008, 2010; Abbatt et al., 2012). In addition, May et al. (2016) report that sea-salt mass concentrations increased in the presence of nearby leads (sea-ice fractures that expose open water) and wind speeds greater than $4 \mathrm{~m} \mathrm{~s}^{-1}$. SSA produced from leads has the potential to alter cloud formation (May et al., 2016), as well as the chemical composition of the tundra snowpack (Simpson et al., 2005; Pratt et al., 2013). Given the thinning of Arctic sea ice and decreasing of multiyear sea ice extent (Cavalieri and Parkinson, 2012; Stroeve et al., 2012), wind-driven production of SSA from blowing snow (on young sea ice) and/or leads could further increase the frequency of surface ODEs in polar spring.

To understand the high-wind ODE mechanism, measurements of SSA are important. However, direct observation of the aerosol in blowing snow is challenging due to the meteorological conditions (strong winds and low visibility). Lidar measurements provide a means of looking through the ice clouds and aerosol layer and can provide particle information, for example, size, density, and vertical profile. In addition to aerosol measurements, isotopologue measurements can be a useful proxy for identifying the lifetime of the air mass and aerosol. Measurements of atmospheric hydrogen deuterium oxide (HDO), which is heavier than $\mathrm{H}_{2} \mathrm{O}$, contain information about the history of the air mass. Simultaneous observations of different tropospheric water isotopologues can provide information on processes related to moisture uptake, exchange, cloud formation, transport/mixing, and temperature upwind of the detected air mass (Schneider et al., 2016). An air mass from the open ocean surface typically contains more HDO than an air mass from the frozen icecovered ocean at high latitude. For example, in Eureka, from February to April, air masses with low HDO content are usually from the ice-covered Arctic Ocean, whereas air masses with high HDO content are usually from ice-free regions of the Atlantic Ocean. Thus, the transport history of the air mass can be evaluated by its water isotopologue ratio. In general, the water isotopologue ratios are expressed in the $\delta$ notation, which relates the observed ratio to the standard ratio of ocean water. The $\mathrm{HDO} / \mathrm{H}_{2} \mathrm{O}$ ratio is normally expressed as the relative deviation $(\delta \mathrm{D})$ from the HDO content of the Vienna Standard Mean Ocean Water (VSMOW) (Craig, 1961), as shown in Eq. (1):

$\delta \mathrm{D}=\left(\frac{R_{\mathrm{m}}}{R_{\text {VSMOW }}}-1\right) \times 1000 \%$,

where $R$ is the $\mathrm{HDO} / \mathrm{H}_{2} \mathrm{O}$ ratio, subscript " $\mathrm{m}$ " denotes the measurement, and $R_{\text {VSMOW }}(0.00031152$, Craig, 1961) is the $\mathrm{HDO} / \mathrm{H}_{2} \mathrm{O}$ ratio in Vienna Standard Mean Ocean Water.

In the polar regions, ice cloud formation and precipitation can change the $\mathrm{HDO} / \mathrm{H}_{2} \mathrm{O}$ ratio. As with the formation of liquid clouds, when ice clouds form, HDO condenses into the ice more efficiently than $\mathrm{H}_{2} \mathrm{O}$, and the air becomes HDO depleted. Thus, the scavenging of HDO (removing of the ice condensate) leaves the air depleted in HDO (low $\delta \mathrm{D}$ values) and provides information about the ice cloud formation (Rayleigh process; Rayleigh and Ramsay, 1894). In addition, blowing-snow events can contribute to atmospheric $\delta \mathrm{D}$ change.

During blowing-snow events, large numbers of snow particles may get into the air. If the air is not saturated, water can sublime from the particles (depending on wind speed, temperature, relative humidity, snow type, etc.; Déry and Yau, 1999, 2001), which reduces their size and eventually leads to the formation of SSA. Yang et al. (2008) parameterized the production flux of SSA, through this process, as a function of the amount of sublimation, snow salinity, snow age, and a few other factors. The sublimation process is normally considered as a non-fractionation process for the ice particles (with no $\delta \mathrm{D}$ changes in the snow/ice crystals). This is because of a low coefficient of self-diffusion of water molecules in ice. When sublimation from ice/snow crystals happens layer by layer, the sublimated molecules have the same $\delta \mathrm{D}$ as when they were frozen in the snow/ice crystals. However, sublimation of blowing snow can change the atmospheric $\delta \mathrm{D}$ through mixing. For example, in $\mathrm{Eu}-$ reka, the mean precipitation $\delta \mathrm{D}$ in March is $-265 \%$ o (2005- 
2013, data provided by F. A. Michel and X. Feng, personal communication, 2016), while the mean atmospheric $\delta \mathrm{D}$ is $-442 \%$ (2006-2014; see Sect. 3.1.1). Thus, mixing of the sublimed HDO-enriched water vapour $(-265 \%)$ from blowing-snow particles with tropospheric background water vapour $(-442 \%$ o can increase HDO content, thus contributing to change in the atmospheric $\delta \mathrm{D}$, and high $\delta \mathrm{D}$ (compared to the Rayleigh fractioning model; see Sect. 2.1.2) should be expected when observing blowing-snow SSA. This process is similar to the phenomenon that $\delta \mathrm{D}$ of water vapour entering the tropical tropopause layer (TTL) is higher than that suggested by Rayleigh models (Moyer et al., 1996; Smith et al., 2006; Blossey et al., 2010). The enrichment of HDO in the TTL is associated with deep convection and sublimation of $\delta \mathrm{D}$-enriched ice from the lower troposphere (Blossey et al., 2010). In summary, the water isotopologue ratio can be used to study SSA formation and transport, and to facilitate the study of blowing-snow ODEs.

Previous case studies identified an ODE initiated from a cyclone in the Beaufort Sea and transported to Eureka on 4-7 April 2011 (Blechschmidt et al., 2016; Zhao et al., 2016a). The meteorological conditions observed at the Eureka Weather Station (EWS) showed that the front arrived at Eureka on 3-4 April. Our previous study showed that the boundary layer on 3-4 April was not stable, and the bromine plume extended from the surface to $2 \mathrm{~km}$. In the present work, by using a 9-year dataset of total column ozone (TCO), column-integrated $\delta \mathrm{D}$, and the tropopause height, additional features are seen in the 2011 case. The $\delta \mathrm{D}$ measurements show that HDO was also depleted during the April 2011 ODE. A similar case was identified in the March 2007 data, showing both ozone and HDO depletion. Satellite images and back-trajectories indicate that both cases are linked to a strong tropospheric cyclone.

This work addresses the following scientific questions, using a variety of measurements and atmospheric models:

- Do current blowing-snow ODE modelling results agree with ground-based measurements at Eureka? How well can models simulate $\mathrm{BrO}$, ozone, and sea-salt aerosol compared to measurements?

- The lifetime of reactive bromine is only a few hours in the absence of recycling. Is there evidence of this recycling over aerosol or blowing-snow/ice particles at Eureka?

- The blowing-snow sublimation process is a key step in producing bromine-enriched sea-salt aerosol. Can isotopologue measurements at Eureka be used to provide evidence of this sublimation process?

These questions are important for our understanding of reactive bromine sources, and for meaningful prediction/modelling of future halogen activation, boundary-layer ozone depletion, and mercury deposition. In the context of a rapidly changing Arctic, these questions are also relevant to environmental change and human health.

\section{Datasets and models}

In this study, ground-based, satellite, and model datasets were combined to produce a comprehensive picture of two ODEs. Ground-based UV and infrared measurements were used to provide ozone column and $\delta \mathrm{D}$, respectively, above Eureka. Ozone profiles measured by ozonesondes were used to identify surface ODEs. Lidar and radar data were used to identify the ice cloud and sea-salt particles. Satellite images from the Moderate Resolution Imaging Spectroradiometer (MODIS) were used to identify the location of the cyclone.

\subsection{Measurements}

\subsubsection{Ozone measurements}

Brewer spectrophotometers measure TCO using direct sunlight at four UV wavelengths (Kerr et al., 1981; Fioletov et al., 2005). The Brewer instrument is the World Meteorological Organization (WMO) Global Atmosphere Watch (GAW) standard for total column ozone measurement (Kerr et al., 1981, 1988). Four Brewers have been deployed at the EWS by Environment and Climate Change Canada (ECCC). Brewer no. 69 is an MKV single spectrophotometer (Adams et al., 2012a) located on the roof of the EWS main building. It was installed in 2004 and has recorded the longest Brewer dataset at Eureka. The current work uses TCO data from Brewer no. 69 analysed using the standard Brewer network operational algorithm (Kerr, 2002), with small changes to the analysis parameters due to the high latitude of the site. Normally, high-quality Brewer TCO data need an ozone air mass factor (AMF) less than 3 (Fioletov et al., 2000; Zhao et al., 2016b). However, to cope with the low-sun condition in the high-latitude spring, following Adams et al. (2012a), the ozone AMF threshold was increased to 5, which is acceptable under low ozone conditions and allows for more days with good data in the early spring. The uncertainty in Brewer TCO measurements is typically less than $1 \%$ (Fioletov et al., 2005), and for high-quality data (e.g., AMF <3) less than $0.6 \%$ (Zhao et al., 2016b).

The EWS has records of electrochemical concentration cell (ECC) ozonesonde measurements since 1992 (Tarasick et al., 2016). Ozonesondes are launched from the EWS weekly year-round and daily during the intensive phase of the Canadian Arctic ACE/OSIRIS Validation Campaigns (20042016) (Kerzenmacher et al., 2005; Adams et al., 2012a). The well-calibrated ECC ozonesondes have precision of 3$5 \%$ for total column and $\sim 5-6 \%$ uncertainty for the 0 $4 \mathrm{~km}$ ozone profile (Tarasick et al., 2016). The Brewer and ozonesonde datasets from 2006 to 2014 are used in this study. 


\subsubsection{Water vapour and HDO measurements}

The CANDAC Bruker IFS 125HR is a Fourier transform infrared spectrometer (FTIR) that is part of the Network for the Detection of Atmospheric Composition Change (NDACC, www.ndacc.org). The Bruker 125HR was deployed at the Polar Environmental Atmosphere Research Laboratory (PEARL) Ridge Lab $\left(86.4^{\circ} \mathrm{W}, 80.1^{\circ} \mathrm{N}\right.$; Fogal et al., 2013) in 2006 (Batchelor et al., 2009). The PEARL Ridge Lab is $610 \mathrm{~m}$ above sea level, $15 \mathrm{~km}$ away from EWS (which is $10 \mathrm{~m}$ above sea level).

The Bruker 125HR provides measurements of multiple trace gas and water vapour (including $\mathrm{H}_{2} \mathrm{O}$ and isotopologues $\mathrm{H}_{2}^{16} \mathrm{O}, \mathrm{H}_{2}^{18} \mathrm{O}$, and $\mathrm{HD}^{16} \mathrm{O}$; Barthlott et al., 2017; Weaver et al., 2017). The tropospheric column-integrated $\mathrm{H}_{2} \mathrm{O}$ and HDO used in the current study were generated as part of the MUSICA (MUlti-platform remote Sensing of Isotopologues for investigating the Cycle of Atmospheric water) project (Schneider et al., 2016) and were used to calculate the $\delta \mathrm{D}$ values (see Eq. 1). Schneider et al. (2016) reported the accuracy of MUSICA $\delta \mathrm{D}$ product to be about $10 \%$. The FTIR data from 2006 to 2014 are used in the present study.

To further interpret the paired $\mathrm{H}_{2} \mathrm{O}-\delta \mathrm{D}$ observations, we adapted a method developed by Noone (2012), which uses the change in $\delta \mathrm{D}$ relative to change in water vapour mixing ratio to provide information about condensation, precipitation, and mixing process in the atmosphere. In general, the method is based on the Rayleigh isotope fractioning model (Rayleigh and Ramsay, 1894; Jouzel and Merlivat, 1984):

$$
\frac{\mathrm{d} \delta}{1+\delta}=(\alpha-1) \frac{\mathrm{d} q}{q},
$$

where $\alpha$ is the equilibrium isotopic fractionation coefficient, which depends on the temperature of the air parcel (Merlivat and Nief, 1967), $\delta$ is the $\delta \mathrm{D}$ value of the air mass, $q$ is the water vapour mixing ratio of the air mass, $\mathrm{d} \delta$ is the change in $\delta \mathrm{D}$, and $\mathrm{d} q$ is the change in water vapour mixing ratio. The Rayleigh model can be applied to both liquid and solid phase formation. The basic assumption of the Rayleigh model is that the condensed phase is formed at isotopic equilibrium with the surrounding vapour and is immediately removed from the air mass after its formation. This is because droplets can be isotopically modified when evaporation occurs (Ehhalt et al., 1963; Stewart, 1975; Jouzel and Merlivat, 1984; Rozanski et al., 1992; Noone, 2012). The Rayleigh model also assumes that, during the formation of ice crystals, there is neither isotopic exchange with the surrounding vapour nor isotopic modification of the ice crystals during their subsequent fallout to the ground (Jouzel and Merlivat, 1984). The additional kinetic fractionation effect (Jouzel and Merlivat, 1984) of ice clouds formed in supersaturation conditions is not applicable for the present study (see Sect. 3.1.2).

MUSICA water vapour isotopologue remote sensing data have two data types (Barthlott et al., 2017). The type-1 data are best suited for tropospheric water vapour distribution studies that disregard isotopologues (e.g., comparison with radiosonde data, analyses of water vapour variability and trends). The type-2 data are designed for analysing moisture pathways by means of $\mathrm{H}_{2} \mathrm{O}-\delta \mathrm{D}$ pair distributions. Thus, the Bruker 125HR/MUSICA water vapour isotopologue type-2 data from 2006 to 2014 were used in the present study. Similar to the Brewer TCO dataset, the solar zenith angle (SZA) filter of the water vapour isotopologue dataset has also been relaxed to expand the temporal coverage of dataset for these high Arctic conditions.

\subsubsection{Cloud and aerosol measurements}

MODIS on board the NASA Terra-1 satellite measures visible and thermal electromagnetic radiation. In this work, false-colour images constructed using bands 2,3 , and 31 are used to identify cyclonic polar low systems (http://modis. gsfc.nasa.gov). The Arctic High Spectral Resolution Lidar (AHSRL) and Millimeter Wave Cloud Radar (MMCR) measurements were used to provide cloud and aerosol information. The AHSRL and MMCR were located at the Zero Altitude PEARL Auxiliary Laboratory (OPAL), which is located at the northwest corner of the EWS site. The AHSRL was developed at the University of Wisconsin and deployed at Eureka from August 2005 to 2010. It has a frequency-doubled diode-pumped Nd: YAG laser at $532 \mathrm{~nm}$ (Bourdages et al., 2009), and measures the particle backscatter cross section $\left(\beta_{\text {lidar }}\right)$ and circular depolarization ratio, which can be used to differentiate between spherical liquid droplets and crystalline particles. The MMCR (Shupe et al., 2010) has been deployed at Eureka since 2005. MMCR measures Doppler velocity, Doppler spectra, spectral width, and equivalent radar reflectivity for clouds, from which the particle backscatter cross section $\left(\beta_{\text {radar }}\right)$ can be determined (Bourdages et al., 2009). Bourdages et al. (2009) proposed a method to categorize atmospheric particles and their mixtures by combining information from the lidar and radar measurements. They calculated a colour ratio defined as the ratio between the radar and lidar backscatter cross sections:

$R_{\text {colour }}=\frac{\beta_{\text {radar }}}{\beta_{\text {lidar }}}$.

The colour ratio is an average property for particles in a measurement volume, and is a good proxy for particle size (Bourdages et al., 2009). The MMCR measures reflectivity from $90 \mathrm{~m}$ to $20 \mathrm{~km}$ in altitude, and is sensitive to volume backscatter cross sections greater than $10^{-14} \mathrm{~m}^{-1} \mathrm{sr}^{-1}$. Following Bourdages et al. (2009), an interpretation in terms of particle size is possible for the colour ratio in the range of $10^{-9}$ to $10^{-3}$, which corresponds to a particle size of about 10 to $150 \mu \mathrm{m}$. This colour ratio method cannot provide particle size information for fine and medium aerosol particles (radius less than $10 \mu \mathrm{m}$ ), but these aerosol layers can be distinguished by $\beta_{\text {lidar }}$ smaller than $2 \times 10^{-5} \mathrm{~m}^{-1} \mathrm{sr}^{-1}$. In the 
present work, we adapted this colour ratio method to distinguish between aerosols, ice clouds, and ice crystals.

\subsection{Models}

\subsubsection{MERRA-2}

The second Modern-Era Retrospective analysis for Research and Applications (MERRA-2) is an atmospheric reanalysis from NASA's Global Modeling and Assimilation Office (GMAO) that provides high-resolution globally gridded meteorological fields using the Goddard Earth Observing System Version 5 data assimilation system (e.g., Bosilovich et al., 2016; Fujiwara et al., 2017). MERRA-2 has a horizontal resolution of $0.625^{\circ}$ in longitude and $0.5^{\circ}$ in latitude. In the present work, vertical profiles of MERRA-2 ozone, temperature, pressure, and scaled potential vorticity (sPV, potential vorticity scaled in "vorticity units" to give a similar range of values at each level; e.g., Dunkerton and Delisi, 1986; Manney et al., 1994; Adams et al., 2013) over Eureka were derived from the MERRA-2 assimilated state variable (ASM) data collection (GMAO, 2015). The profile data are on 72 model layers with approximately $1 \mathrm{~km}$ vertical spacing near the tropopause, and $3 \mathrm{~h}$ temporal resolution. Tropopause locations are calculated from MERRA-2 according to dynamical (the PV-based, so-called dynamical tropopause) and temperature gradient (so-called thermal tropopause) definitions using the JEt and Tropopause Products for Analysis and Characterization (JETPAC) package described by Manney et al. (2011); here we used the thermal tropopause height (WMO, 1992) in Sect. 3.1.

\subsection{2 pTOMCAT}

The Cambridge Parallelised-Tropospheric Offline Model of Chemistry and Transport (pTOMCAT) is a global 3-D chemistry transport model (CTM) (O'Connor et al., 2005; Yang et al., 2005). The forcing files (temperature, wind, and humidity fields) for pTOMCAT are 6-hourly ERA-Interim data from the European Centre for Medium-Range Weather Forecasts (ECMWF) (Dee et al., 2011; Fujiwara et al., 2017). Monthly sea-ice coverage and sea surface temperatures are taken from the Hadley Centre Sea Ice and Sea Surface Temperature (HadISST) dataset (Rayner et al., 2003). The model's horizontal resolution is $2.8^{\circ} \times 2.8^{\circ}$ (longitude $\times$ latitude) with 31 vertical layers from the surface to about $10 \mathrm{hPa}$ at the top layer.

A detailed process-based SSA scheme has been implemented in the model (Levine et al., 2014) based on the work of Reader and McFarlane (2003). Since the Levine et al. (2014) work, some updates have been introduced to the model, including improved precipitation, dry deposition velocities on snow for inorganic bromine species, and reduced snow salinity applied to the blowing snow (Legrand et al., 2016). Both open-ocean-sourced and sea-ice-sourced SSA
(OO-SSA and SI-SSA) are tagged in order to track their history. Both OO-SSA and SI-SSA are in 21 size bins covering the range of $0.1-10 \mu \mathrm{m}$ in dry radius (Rhodes et al., 2017). To study the transport of the SSA in the present work, SISSA with dry radius at $0.25,1$, and $5 \mu \mathrm{m}$ were used in the comparison with another particle dispersion model.

The tropospheric bromine chemistry scheme in pTOMCAT is based on the work of Yang et al. $(2005,2010)$. The bromine source includes inorganic sea salt from both the open ocean and the sea-ice zone (from blowing snow; Yang et al., 2008), and halocarbons from long-lived (e.g., $\mathrm{CH}_{3} \mathrm{Br}$ ) and very short-lived substances (VSLSs). The emissions of the VSLSs $\left(\mathrm{CHBr}_{3}, \mathrm{CH}_{2} \mathrm{Br}_{2}, \mathrm{CH}_{2} \mathrm{BrCl}, \mathrm{CHBr}_{2} \mathrm{Cl}\right.$, and $\mathrm{CHBrCl}_{2}$ ) are based on the original work (scenario 5) of Warwick et al. (2006), except for emissions of $\mathrm{CH}_{2} \mathrm{Br}_{2}$, which were updated to $50 \%$ of the original flux to allow a closer match to the observation (Yang et al., 2014). Heterogeneous reactions that reactivate inactive inorganic bromine species (such as $\mathrm{HBr}$ ) to active Br radicals, on both atmospheric background particles (offline data taken from Heintzenberg et al., 2000) and the SSA produced from sea spray and blowing snow (online calculated) have been included in this model integration. In general, the bromine flux from SSA depends on (1) the rates of SSA production from both open ocean and blowing snow on sea ice, and (2) the bromine depletion factors for SSA, which are size dependent as observed (Yang et al., 2008, 2010). The SSA production rate is calculated using the rate at which snow particles are lifted from the surface and subsequent sublimation (which depends on wind speed, temperature, relative humidity, and the age of snow). More details about the calculation of bromine release flux from blowing snow can be found in Zhao et al. (2016a). The current work uses the transported SI-SSA information from pTOMCAT to make a direct comparison with ground-based measurements.

\subsubsection{The UKCA model}

UKCA is a global chemistry-climate model (CCM); its dynamical core is the Met Office Unified Model (UM) version 7.3 running in the HadGEM3-A configuration (Morgenstern et al., 2009). The UMUKCA-CheST version contains a comprehensive stratospheric chemistry scheme as well as a detailed tropospheric chemistry scheme, including isoprene chemistry and improved bromine chemistry in both the troposphere and stratosphere (Braesicke et al., 2013; Yang et al., 2014). The model's horizontal resolution is $3.75^{\circ} \times 2.5^{\circ}$ with 60 vertical layers from the surface to about $84 \mathrm{~km}$. A nudged UKCA version (forcing by ERA-Interim, the same meteorological fields as pTOMCAT) is used in this study. Tropospheric bromine chemistry was introduced to UKCA based on the work in pTOMCAT (Yang et al., 2005, 2010). In general, UKCA and pTOMCAT share the same SSA production flux from the same particle size bins (and thus have same bromine release flux). However, unlike pTOMCAT, UKCA 
does not trace the SSA transport after the emission; therefore, there is no online SSA being taken into account in the heterogeneous rate calculation (only a monthly climatology aerosol dataset from the CLASSIC aerosol scheme was used; Johnson et al., 2010). In terms of dynamics, the UM model is much different to the atmosphere-only pTOMCAT in many aspects, for example from the boundary layer vertical mixing scheme to the cloud parameterization; see more details in Russo et al. (2011) and Ruti et al. (2011).

The UKCA model successfully simulated the 2011 blowing-snow-induced ODE for our previous study (Zhao et al., 2016a). The difference between the present work and our previous study (Zhao et al., 2016a) is mainly snow salinity, as this parameter has recently been updated based on samples collected in the Weddell Sea (Legrand et al., 2016). The new surface snow salinity (top $10 \mathrm{~cm}$ snow layer, about 0.3 practical salinity unit, the same value as pTOMCAT) in the present work is smaller by an order of the value used in Zhao et al. (2016a), which was the column mean salinity (Sander et al., 2003; Yang et al., 2008).

\subsubsection{FLEXPART}

The Lagrangian FLEXible PARTicle dispersion model (FLEXPART) was first released in 1998 for calculating the long-range and mesoscale dispersion of air pollutants from point sources. It has been used to examine source regions for aircraft, satellite, ground-based station, and shipbased studies (e.g., Stohl et al., 2005; Begoin et al., 2010; Gilman et al., 2010; Blechschmidt et al., 2016; Lutsch et al., 2016). In the present work, FLEXPART is run backwards in time for a group of passive SSA tracers that are transported by winds from $0.5^{\circ} \times 0.5^{\circ}$ resolution NCEP Climate Forecast System Version 2 (CFSv2) 6-hourly products (http://rda.ucar.edu/datasets/ds094.0/; Saha et al., 2014). To compare with pTOMCAT modelled SSA, we used three different-sized SSA tracers $(0.25,1$, and $5 \mu \mathrm{m})$ in the simulation, and released them at Eureka on two different grids. One grid was $0.4^{\circ} \times 0.4^{\circ}(\sim 20 \mathrm{~km} \times 20 \mathrm{~km})$ and had Eureka at the centre of the grid, and the other grid $2.8^{\circ} \times 2.8^{\circ}$ $(\sim 56 \mathrm{~km} \times 310 \mathrm{~km})$ was selected to match one of the pTOMCAT grids that includes Eureka.

\section{Results}

\subsection{Surface ozone depletion and water vapour measurements}

In the atmosphere, most ozone $(\sim 90 \%)$ is in the stratosphere. Thus, the TCO is a function of tropopause height, with a low tropopause generally increasing TCO. In contrast, $\mathrm{H}_{2} \mathrm{O}$ and $\mathrm{HDO}$ are most abundant in the lower troposphere, thus precipitable water vapour (PWV) and column-integrated $\delta \mathrm{D}$ may provide information about the meteorological conditions in the lower troposphere. TCO, thermal tropopause
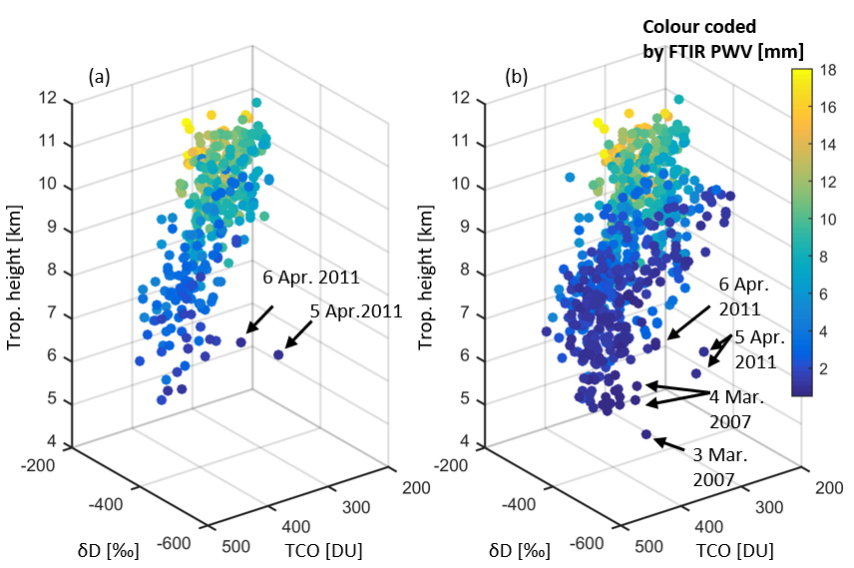

Figure 1. 3-D scatter plots of $\delta \mathrm{D}$, total ozone column, tropopause height, and total precipitable water. TCO data in (a) are from Brewer no. 69 measurements. TCO data in (b) are from MERRA-2 model output. Tropopause heights are WMO temperature gradient tropopause values calculated from MERRA-2. The $\delta \mathrm{D}$ and PWV are from the Bruker 125HR FTIR measurements.

height, and $\delta \mathrm{D}$ can be combined in a 3-D scatter plot that contains dynamical and chemical information. TCO $(\delta \mathrm{D})$ is governed not only by tropopause height but also by other factors, e.g., chemical loss (transport). However, in general, there is a simple inverse relation between these three variables. For example, when the tropopause height reaches a maximum in summer, TCO is at its minimum value, while $\delta \mathrm{D}$ is at its maximum value. In the winter, as the tropopause height decreases, TCO reaches its maximum value, while $\delta \mathrm{D}$ is at its minimum value. Figure 1a shows the 3-D scatter plot generated by merging 9 years of Brewer TCO, MERRA-2 tropopause height, and Bruker $125 \mathrm{HR} \delta \mathrm{D}$. The data points are colour-coded by PWV amount (measured by the Bruker 125HR). The 3-D scatter plot reveals the general linear relation between each pair of the three variables as discussed above. The low $\delta \mathrm{D}$ outliers marked in Fig. 1a are on 5 and 6 April 2011 (when $\delta \mathrm{D}$ values are -503 and $-505 \%$, respectively), suggesting unusual meteorological conditions (cyclone events).

The size of the combined dataset is limited by the Brewer TCO measurements, which only start in late March. To expand the dataset, the MERRA-2 TCO was used instead of Brewer TCO. The MERRA-2 TCO for Eureka has a high correlation $(R=0.99)$ and a low positive bias $(1.6 \%)$ compared to Brewer TCO (not shown here). The resulting increase in the number of coincident data points is seen in Fig. 1b, which reveals a similar event for 3 and 4 March 2007 $(-529$ and $-551 \%$ or $\delta \mathrm{D}$ values, respectively). Figure 2 shows the box-and-whisker plot of Bruker 125HR monthly $\delta \mathrm{D}$ and PWV measurements. The median (mean) $\delta \mathrm{D}$ values for March and April at Eureka are -443 (-442) and -410 $(-408) \%$, respectively. The $\delta \mathrm{D}$ value describes the relative deviation of HDO content from the standard mean ocean wa- 

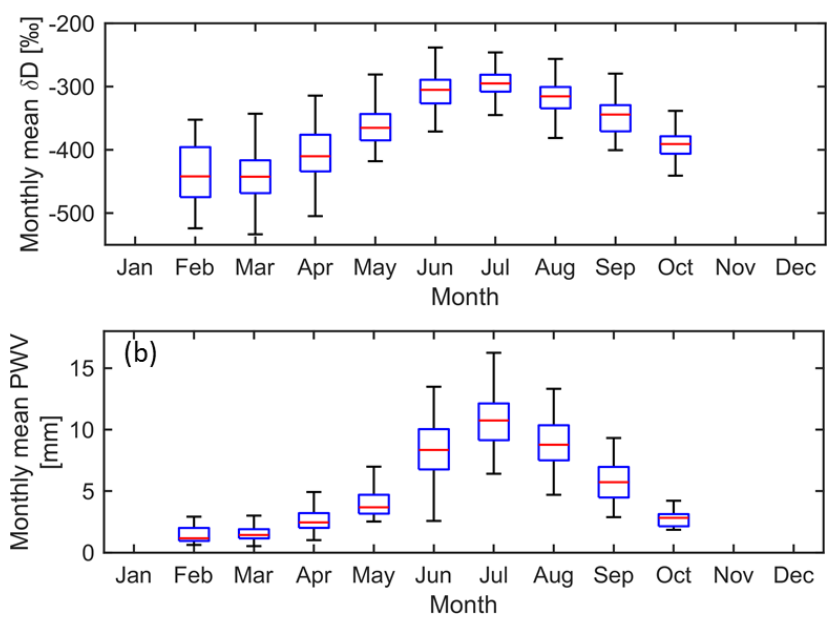

Figure 2. Bruker 125HR monthly (a) $\delta \mathrm{D}$ and (b) PWV. On each box, the central red mark is the median, the edges of the blue box are the 25th and 75th percentiles, and the black whiskers extend to the most extreme data points not considered outliers. The outliers are defined as greater than $\mathrm{q} 3+1.5(\mathrm{q} 3-\mathrm{q} 1)$ or less than $\mathrm{q} 1-1.5$ (q3 $-\mathrm{q} 1)$, where $\mathrm{q} 1$ and $\mathrm{q} 3$ are the 25 th and 75 th percentiles of the sample data, respectively (Tukey, 1977).

ter. Thus, the HDO value on 4 March 2007 is $55.1 \%$ less than the standard; the $\delta \mathrm{D}$ value is $24.7 \%$ less than the March mean (comparing -551 and $-442 \%$ ). Similarly, the $\delta \mathrm{D}$ value on 5 April 2011 is $23.8 \%$ less than the monthly mean of April (comparing -503 and -408\%o). The coincidence of these two events (2007 and 2011) on the 3-D plot (Fig. 1b) indicates they may share similar dynamical and chemical causes. Figure 2a shows that the median (mean) PWV is 1.4 (1.7) $\mathrm{mm}$ in March and 2.5 (2.6) $\mathrm{mm}$ in April. The daily mean PWV value was only $0.5 \mathrm{~mm}$ on 4 March 2007 and was $1.0 \mathrm{~mm}$ on 5 April 2011, which indicates relatively dry conditions for these two events. A more detailed discussion of HDO depletion is presented in Sect. 3.3.

Figure $3 \mathrm{a}$ and $\mathrm{b}$ shows Eureka ozonesonde records from February to March 2007 and March to May 2011. The 0$4 \mathrm{~km}$ ozone profiles on 3 and 4 March 2007 and 4 and 6 April 2011 are indicated in the figure. Surface ozone depletion during these two events can be seen, although the 2007 event is weaker than the 2011 event. Figure $3 \mathrm{c}$ and d shows $0-8 \mathrm{~km}$ relative humidity $(\mathrm{RH})$ values measured by radiosondes. The low RH and PWV during these two events (see details in Sect. 3.3.1) can facilitate SSA production through the blowing-snow mechanism proposed by Yang et al. (2008).

\subsubsection{Chemical model results}

Figure 4 shows the ozone and $\mathrm{BrO}$ volume mixing ratio profiles over Eureka for the 2007 event obtained from ozonesondes and model simulations. The UKCA model has a more advanced boundary layer parameterization scheme, and it reproduced a strong boundary layer ODE from 3 to 5 March.
This thin shallow surface ozone depletion layer (see the UKCA result in Fig. 4 b, minimum value $\sim 5$ ppbv) is similar to the ozonesonde measurements (Fig. 4a, minimum value $\sim 1 \mathrm{ppbv}$ ) from 3 to 5 March (with almost no $\mathrm{BrO}$ in the boundary layer, Fig. 4d). In contrast, pTOMCAT produces $\mathrm{BrO}$ enhancements that are well mixed in the lowest several kilometres (Fig. 4c). The ozonesondes measured 40 50 ppbv background ozone for $2-4 \mathrm{~km}$, but both pTOMCAT and UKCA modelled about $10 \mathrm{ppbv}$ less at these altitudes. The BrO VMR from both models is less than 5 pptv. Since there is a difference in how these two models simulate the boundary layer, there will be differences in their ability to produce ozone depletion events that can be related to the processes in the boundary layer.

One interesting feature in Fig. 4 is that ozone depletion was also observed from 1 to 2 March. The ozonesonde observations on these 2 days (Fig. 4a) indicate the presence of a thin ozone-depleted layer at $800-900 \mathrm{~m}$ that is above the boundary layer (see also Fig. 5a and b). However, this aloft layer is not captured by either model. During 1 to 2 March, the pTOMCAT ozone mixing ratio below $2 \mathrm{~km}$ is smaller than the UKCA result. Also, pTOMCAT produces large BrO amounts (which also show a diurnal cycle) compared to UKCA. Figure $5 \mathrm{c}$ and $\mathrm{f}$ also show that the thermal boundary layer heights (calculated from radiosonde measurements) on 1 March 2007 and 4 April 2011 are both about 900-1000 m, which are much higher than the boundary layer heights on 3 to 5 March 2007 and 6 April 2011. The radiosonde potential temperature profiles indicate the breakdown of the surface temperature inversion when the cyclones arrived. The ERAInterim boundary layer data (Dee et al., 2011) indicate the surface mixing conditions for the 2007 event and the 2011 event are not the same. However, it is likely that the ERAInterim boundary layer height (BLH) data underestimated surface mixing for the 2007 event.

Figure 6 shows the ozone and $\mathrm{BrO}$ volume mixing ratio profiles over Eureka for the 2011 event. The highlight of the re-run of the UKCA model for 2011 is the increased $\mathrm{BrO}$ volume mixing ratio. In our previous study (Zhao et al., 2016a), UKCA only modelled about half of the maximum BrO VMR compared to ground-based measurements. The previous sensitivity study found that even doubling the bromine release flux from the source region in the model did not increase the BrO VMR over Eureka because of very low ozone VMR ( $<1 \mathrm{ppbv})$ in this case (Zhao et al., 2016a). However, in this re-run, the decreased snow salinity in the model input (which decreases the bromine release flux from the source region) surprisingly increased the modelled $\mathrm{BrO}$ VMR (to $\sim 23$ pptv) over Eureka, which is comparable to the ground-based MAX-DOAS measurements of $\sim 21 \mathrm{pptv}$ (the UKCA previously modelled $\sim 13$ pptv; see Zhao et al., 2016a, for more details). The reduced bromine flux from the source region reduced the depletion of ozone along the trajectory, which in turn preserved the high concentration of bromine. In general, this result supports the hypothesis of 

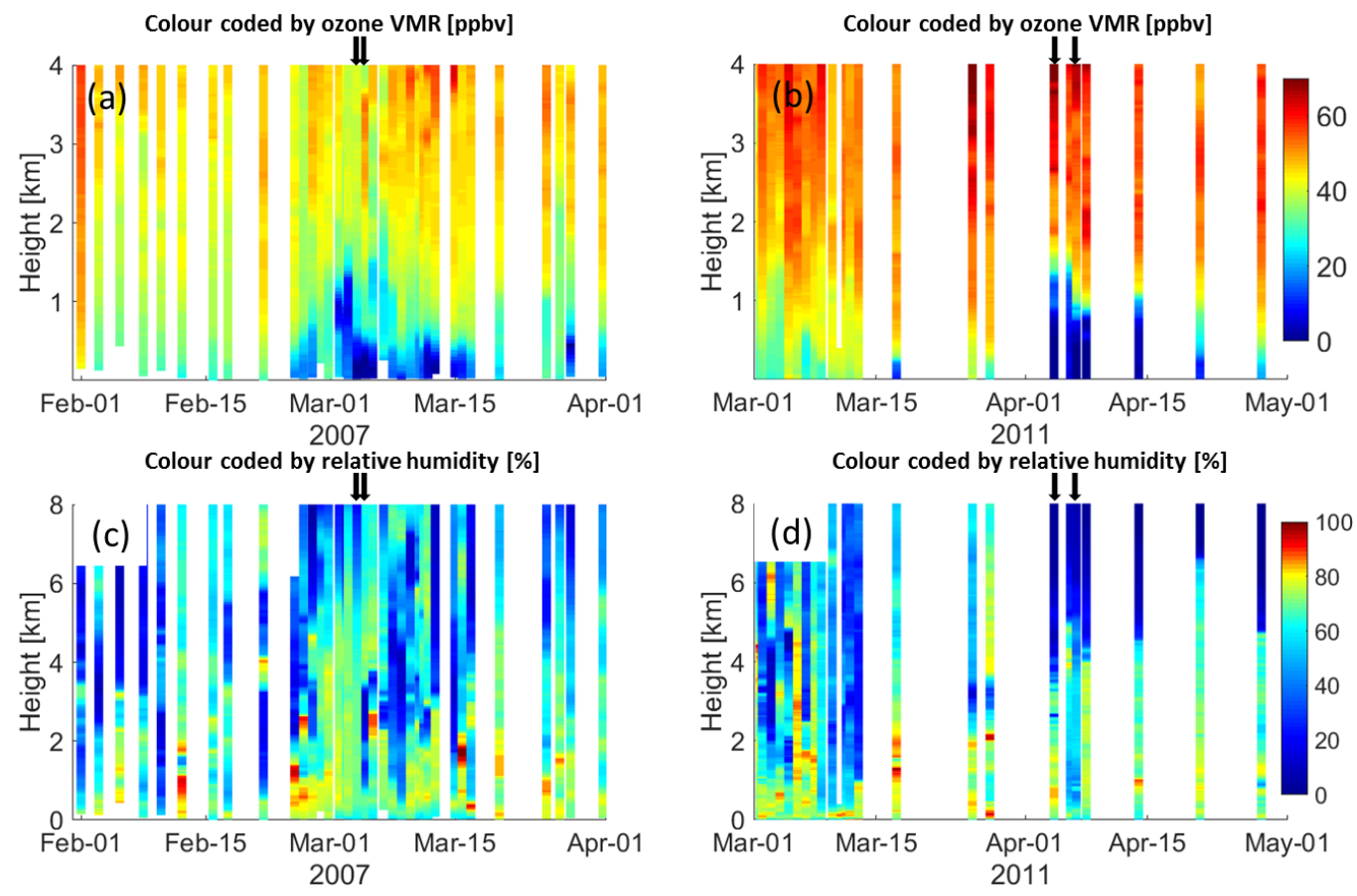

Figure 3. Panels (a) and (b) show 0-4 km ozone and (c) and (d) 0-8 km relative humidity profiles above Eureka from ozonesondes and radiosondes. (a, b) From 1 February to 1 April 2007 and (b, d) from 1 March to 1 May 2011. The measurements on 3 and 4 March 2007 and 4 and 6 April 2011 are indicated by the arrows.

Zhao et al. (2016a) that during a strong surface ODE (ozone VMR $<1$ ppbv), the bromine concentration and partitioning can be significantly affected by the near-zero ozone concentration. pTOMCAT also captured the 2011 event, but the results are not as good as those of the UKCA model. This could be due to the difference in the models' dynamics in the boundary layer (Hoyle et al., 2011; Ruti et al., 2011), model resolution, and the background aerosol scheme (Yang et al., 2005, 2010; Zhao et al., 2016a).

Comparing the measured and modelled ozone profiles for the two events (see Figs. 4 and 6), the surface ozone depletion on March 2007 is weaker than that during the April 2011 event. The weaker ODE in 2007 is likely due to insufficient sunlight and/or boundary layer mixing conditions. The first sunrise at Eureka is on 21 February. On 4 March, the daylight length is only $7.5 \mathrm{~h}$ and the maximum solar elevation angle is only $3.7^{\circ}$, but on 4 April the daylight length is $17.5 \mathrm{~h}$ and maximum solar elevation angle is $16^{\circ}$. Note that the insufficient sunlight will make Reaction (R2) the rate-limiting step in the bromine reaction cycle (R1 to R4). In addition, the strength of the two cyclonic polar low systems was different (discussed in Sect. 3.1.3).

\subsubsection{Air mass history}

To examine the history of the ozone-depleted air mass and aerosol transport, FLEXPART (Stohl et al., 2011) is used in the present study. Figure 7 shows some of the FLEX-
PART SSA-TRACER total column sensitivities (in units of seconds), which, when multiplied by emission flux (20000 particles $\mathrm{h}^{-1}$ in our simulations), provides a simulated concentration at the receptor (Stohl et al., 2013). As knowledge of the SSA type is limited, simulations are kept as simple as possible. The SSA-TRACER had a scavenging scheme (both wet and dry deposition) applied (Seibert and Frank, 2004; Stohl et al., 2005, 2011) but had no assumption on its lifetime. We used 20000 tracer particles for each release. The release times were set to be coincident with the Bruker $\delta \mathrm{D}$ measurements, and the duration of each release was $1 \mathrm{~h}$. Each backwards run lasts for 6 days, and the release heights were set to 0 to $500 \mathrm{~m}$ and 1500 to $2000 \mathrm{~m}$, respectively. The particle release location areas were set to use the coarse grid from pTOMCAT (which includes Eureka) and a much finer grid (only $2 \%$ of pTOMCAT grid size, not shown here) as described in Sect. 2.2.4. The aerosol tracers released in all backwards simulations show sensitivity to the Beaufort Sea region, and the plumes reveal the structure of the cyclones (see Fig. 7).

MODIS false-colour images (Fig. 8) show cloud tops of two polar cyclones, which formed over the Beaufort Sea during both periods of interest. The ERA-Interim data (see Fig. 9) show that the wind speed in the cyclone increased to 20 and $24 \mathrm{~m} \mathrm{~s}^{-1}$ for the 2007 and 2011 cases, respectively, and the BLHs increased to 710 and $800 \mathrm{~m}$ for those two events, respectively. Thus, the cyclone in 2007 was weaker 


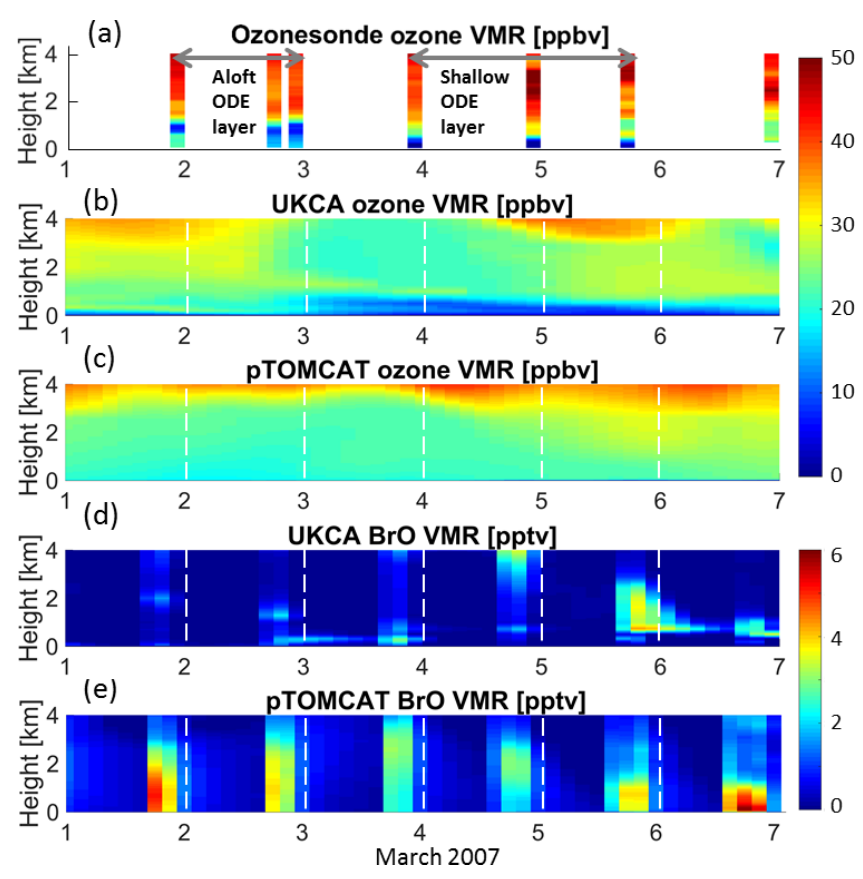

Figure 4. Ozone and $\mathrm{BrO}$ volume mixing ratio profiles from 0 to $4 \mathrm{~km}$ over Eureka from 1 to 7 March 2007 (UTC): (a) ozonesonde measurements, (b) UKCA modelled ozone profile, (c) pTOMCAT modelled ozone profile, (d) UKCA modelled BrO profile, and (e) pTOMCAT modelled BrO profile. Grey horizontal doubleheaded arrows in (a) indicate the periods when ozonesondes measured the aloft ozone depletion layer and the shallow depletion layer.

than the one in 2011. In general, these observations and model simulations confirm that the ozone-depleted air mass and aerosols that were observed at Eureka during those two events were generated in high-wind conditions in the Beaufort Sea region and then transported by the polar cyclones.

\subsection{Cloud and aerosol}

Among many different proposed bromine sources (Abbatt et al., 2012), we focused on the SSA in this study. In the Arctic spring, the SSA concentration depends on meteorological, sea-ice, and snow conditions (Nilsson et al., 2001; Rannik, 2001; Lewis and Schwartz, 2004; Yang et al., 2008; May et al., 2016). Wind speed, RH, sea surface and air temperature gradient, water/ice/snow salinity, and removal processes (wet and dry deposition) will all affect the SSA formation and concentration. For the present work, the meteorological conditions for the 2007 and 2011 events support the work of Yang et al. (2008), which reported that SSA production rate from snow can be significant in high-wind conditions.

\subsubsection{Lidar and radar observations}

The lifetime of SSA in the atmospheric boundary layer can range from minutes to days, depending on its size and me- teorological conditions. Fine SSA (diameter $<2.5 \mu \mathrm{m}$ ) has slower deposition rates compared to medium-sized SSA (diameter from 2.5 to $10 \mu \mathrm{m})$. Following the work of Yang et al. (2008), large SSA (diameter $>10 \mu \mathrm{m}$ ) was not included in pTOMCAT and UKCA due to their short lifetime (faster dry deposition rate) in the atmosphere. In the Arctic spring, the low temperature makes the SSA contributed from the open ocean less important. Thus, although pTOMCAT includes both OO-SSA and SI-SSA, only the latter is considered in this study. For these two events, both ground-based observations and model data revealed high aerosol concentration during the ODEs. For the 2011 case, the aerosol extinction measurements from a ground-based MAX-DOAS instrument and the cloud measurements from the MMCR were presented in our previous study (Zhao et al., 2016a). In the present work, we compare the pTOMCAT SI-SSA data during the 2007 event with aerosol and cloud measurements from the AHSRL and MMCR (note that the MAX-DOAS measurements started in 2010, and the AHSRL measurements ended in 2010).

Figure 10 shows the comparison of lidar/radar profile data with the pTOMCAT SI-SSA VMR profile. Figure 10a shows the measurement time for the ozonesondes (dashed lines) and Bruker 125HR (green lines/boxes). Figure 10b and c show the linear depolarization and backscatter cross sections measured by the lidar. The backscatter cross sections measured by the lidar $\left(\beta_{\text {lidar }}\right)$ and $\operatorname{radar}\left(\beta_{\text {radar }}\right)$ were used to calculate the colour ratio (see Fig. 10d).

The cyclonic air mass arrived at Eureka on 18:00 UTC 1 March. AHSRL linear depolarization data indicate that there was an aloft layer of particles (Fig. 10b, area $\alpha$ ) that showed high depolarization from 30 to $50 \%$ at $700-1000 \mathrm{~m}$. The colour ratio (Fig. 10d) for this layer was in the range of $10^{-5}$ to $10^{-3}$, indicating that it was ice cloud (vapour and ice crystals) with ice precipitation (see Fig. 10 in Bourdages et al., 2009 for the classification chart), and that the effective radius of the particles was in the range of 50-150 $\mu \mathrm{m}$. This layer of ice cloud was coincident with the aloft ODE layer (for example, the ozonesonde at 23:28 on 1 March has the greatest ozone depletion (to $7 \mathrm{ppbv}$ ) at $870 \mathrm{~m}$ ) as shown in Fig. 11. Bourdages et al. (2009) described the lidar and radar measurements from 4 to 5 March 2007 in detail. An ice crystal layer (high depolarization, low colour ratio) is seen from the surface to $300 \mathrm{~m}$ from 14:00 to 24:00 UTC on 4 March (Fig. 10d, area $\gamma$ ). A thin aerosol layer (low depolarization, low colour ratio, $300-500 \mathrm{~m}$ ) for that period is also seen (Fig. 10c, area $\beta 2$ ). Ice clouds were identified in the middle troposphere from 16:00 UTC on 4 March to 08:00 UTC on 5 March (Fig. 10c, area $\beta 3$ ). These shallow layers of ice crystals (area $\gamma$ ) and aerosol (area $\beta 2$ ) were coincident with the shallow ODE layer (for example, the ozonesonde at 23:16 on 4 March shows ozone depletion to $1 \mathrm{ppbv}$ from the surface to $200 \mathrm{~m}$, with the ozone mixing ratio increasing to $32 \mathrm{ppbv}$ at $650 \mathrm{~m}$ ) as shown in Fig. 11. Another two aerosol-enhanced events were also observed as indicated in Fig. 10c (areas $\beta 1$ 

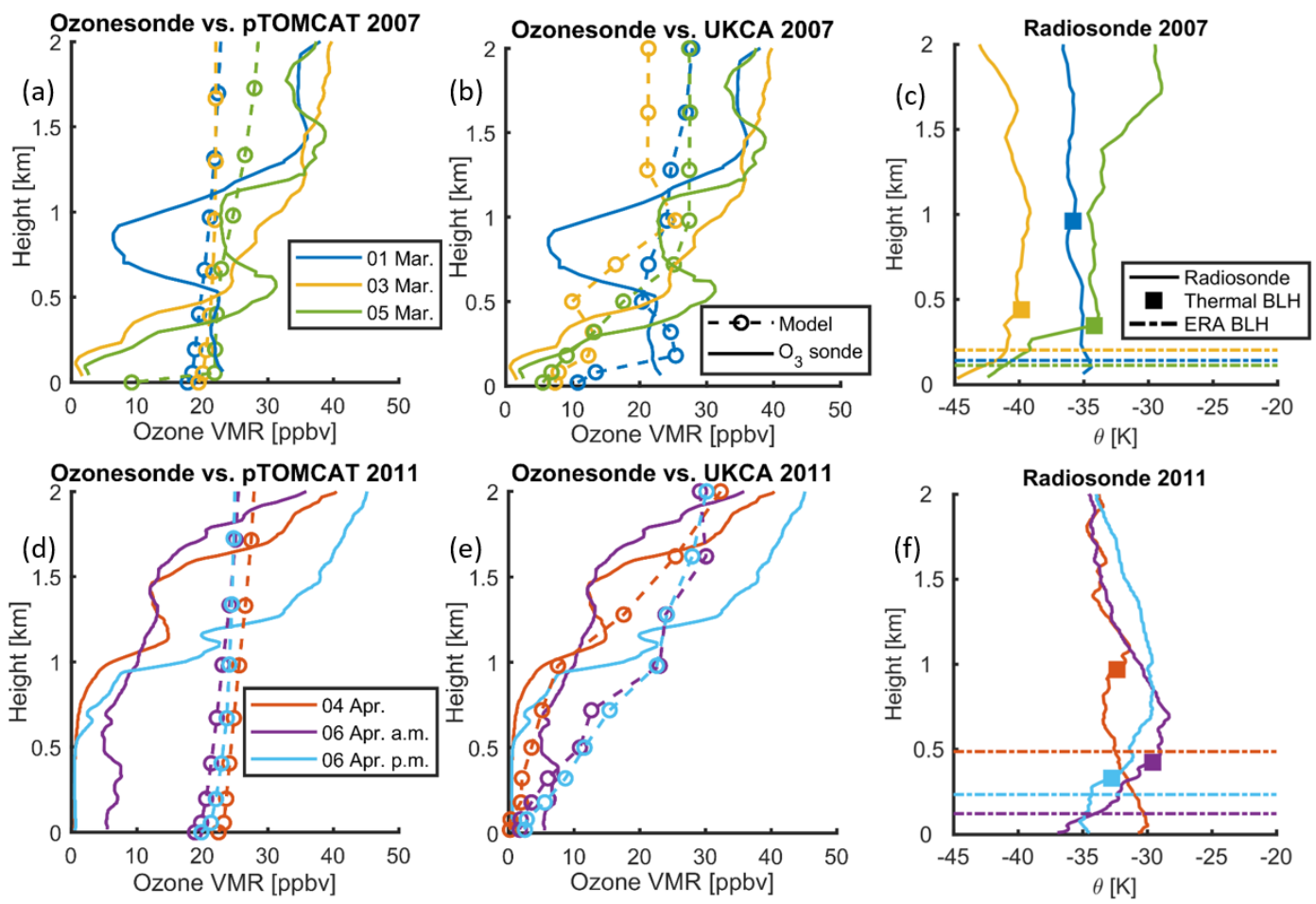

Figure 5. Observed and modelled ozone profiles from 0 to $2 \mathrm{~km}$ in March 2007 (a, b) and April 2011 (d, e): ozonesonde vs. (a, d) pTOMCAT and $(\mathbf{b}, \mathbf{c})$ UKCA. Modelled ozone profiles are shown by dashed lines with circle markers, and measured profiles are shown by solid lines. Potential temperature $(\theta)$ profiles from radiosondes are shown in (c) and (f): measured profiles are shown by solid lines, calculated thermal boundary layer heights (maximum potential temperature gradient) are shown by solid squares, and ERA-Interim boundary layer heights are indicated by dashed horizontal lines.

and $\beta 4$ ). In addition, small water clouds were observed at 2.2 to $2.5 \mathrm{~km}$ between 10:00 and 14:00 UTC on 5 March and at $2.4 \mathrm{~km}$ at about 01:00 UTC on 6 March. A very thin water cloud was observed at about $1.8 \mathrm{~km}$ between 08:00 and 14:00 UTC on 6 March.

The lidar/radar observations of the ice clouds, ice crystal, and boundary layer aerosol from the cyclonic air mass explain why strong HDO depletion was observed coincident with the arrival of the front. Interestingly, the ice cloud was at the same height as the aloft ODE layer. The lidar/radar observations also reveal deposition (falling snow and ice crystals) processes at Eureka; the ice precipitate has high depolarization and vertically aligned fall streaks. The prolonged surface ODE on 4 and 5 March could be due to the deposition of bromine-enriched particles onto the local snowpack.

In general, the lidar, radar, and ozonesonde data confirmed that the aloft ODE layer observed in March 2007 was more likely due to blowing snow than to convection (e.g., McElroy et al., 1999; Simpson et al., 2017). As pointed out by Simpson et al. (2017), surface-based ODEs can be propagated aloft when aerosol extinction is large $\left(>0.1 \mathrm{~km}^{-1}\right)$; however, the presence of aerosol particles aloft is not sufficient to produce $\mathrm{BrO}$ aloft. Thus, to distinguish these different sources of ODEs aloft (blowing snow induced or convection induced), multiple measurements (lidar, radar, sondes, etc.) are necessary.

\subsubsection{Model results}

The modelled SI-SSA from pTOMCAT in three bins $(0.25,1$, and $5 \mu \mathrm{m}$ ) captured some features of the transported aerosols during this period (Fig. 10e to g). For example, the three aerosol events seen in Fig. 10c (areas $\beta 1, \beta 2$, and $\beta 4$ ) can also be found in the modelled SI-SSA. Modelled $5 \mu \mathrm{m}$ SISSA is most abundant in area $\beta 1$, whereas 1 and $0.25 \mu \mathrm{m}$ SISSA are most abundant in area $\beta 4$. Back-trajectory results show that the fine aerosol on 6 March was transported from the north, whereas the medium-sized SSA on 1 March came from the south (not shown here). A weak shallow aerosol layer on 4 March was also captured by pTOMCAT(see area $\beta 2$ ), and it was transported from the west (as from the cyclonic air mass).

As discussed in Sect. 3.1, the modelled and observed ozone depletion for the 2007 event is weaker than that for 2011 event. In addition, pTOMCAT modelled ozone depletion was less than that in the UKCA model (see Fig. 5). One possible explanation is that pTOMCAT did not fully capture the production of SSA during the blowing snow. Figures 7 and 9 show that the high-wind areas for the 2011 event were 

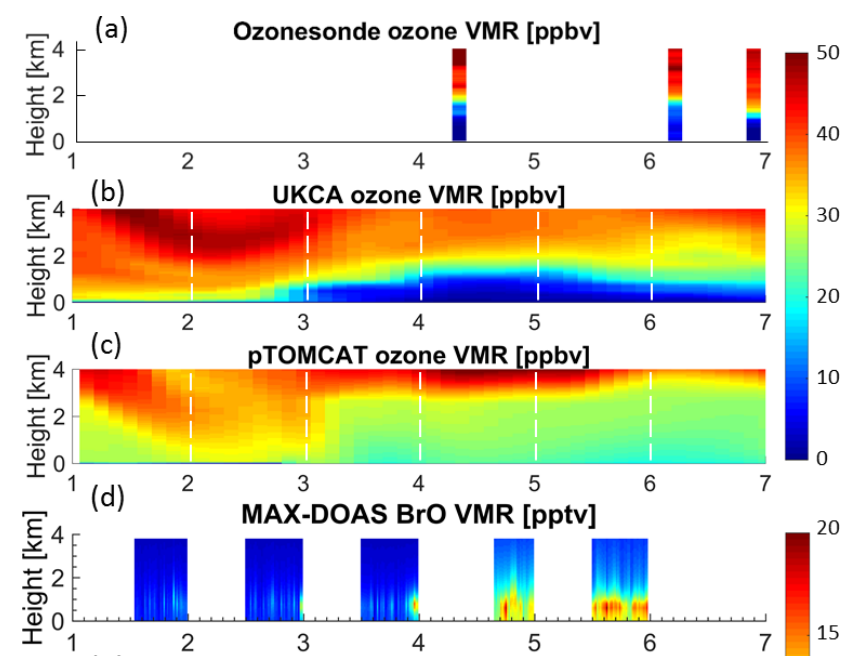

(e)
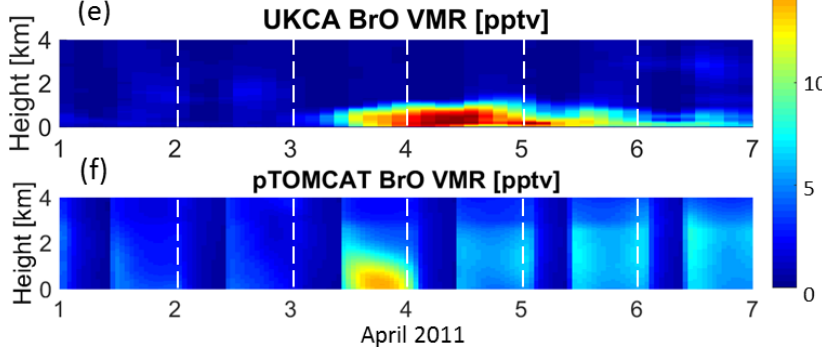

Figure 6. Ozone and $\mathrm{BrO}$ volume mixing ratio profiles from 0 $4 \mathrm{~km}$ over Eureka from 1 to 7 April 2011 (UTC): (a) ozonesonde measurements, (b) UKCA modelled ozone profile, (c) pTOMCAT modelled ozone profile, (d) MAX-DOAS retrieved BrO profile, (e) UKCA modelled $\mathrm{BrO}$ profile, and (f) pTOMCAT modelled $\mathrm{BrO}$ profile.

over sea ice, whereas the high-wind areas for the 2007 event were close to land. Because of the coarse model grid resolution, both models underestimated the production of SSA in that close-to-land cyclone case. Thus, the underestimated SSA may reduce the strength of the ODEs.

As discussed in Sect. 3.2.1, none of the chemical models used in the present study reproduced the aloft ozone depletion layer. pTOMCAT results show that there was almost no SI-SSA during that period (see Fig. $10 \mathrm{e}-\mathrm{g}$, area $\alpha$ ). Thus, the production and deposition mechanisms of SI-SSA in the models still need further investigation. For example, the SI-SSA deposition rates (wet and/or dry) might be too high in this case. In general, this comparison of lidar/radar measurements and modelled SI-SSA provides support for the blowing-snow SSA production mechanism and suggests that further improvements in SI-SSA modelling are important to improve blowing-snow ODE simulations.
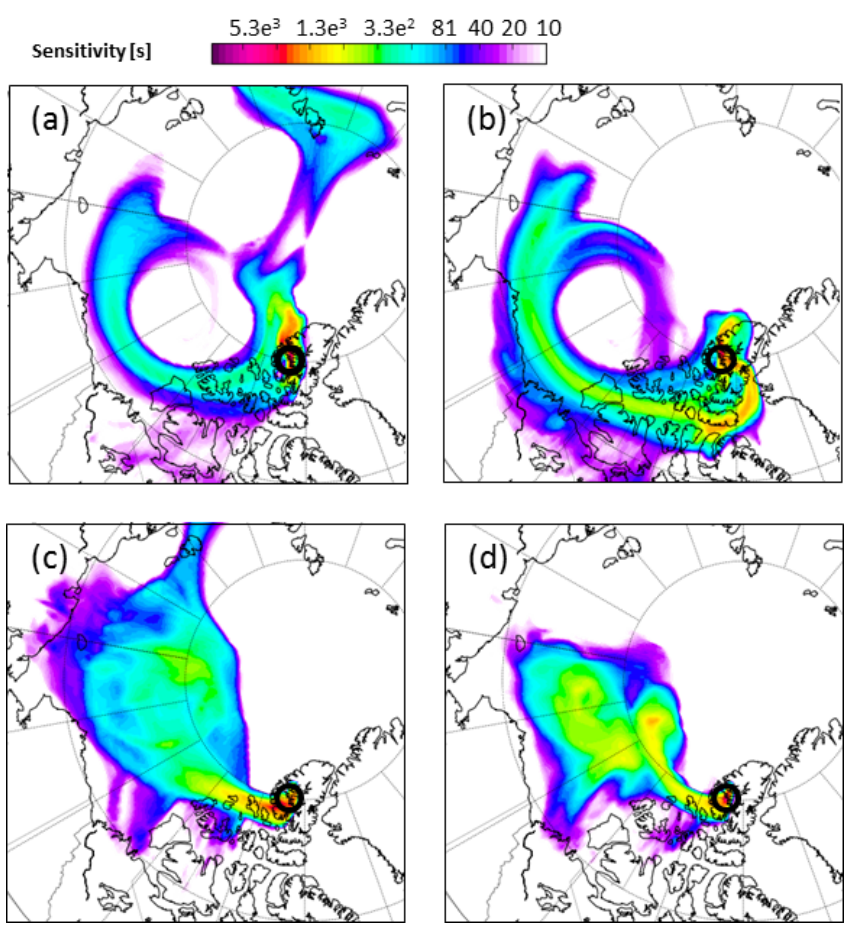

Figure 7. FLEXPART SSA-TRACER 6-day backward run showing total column sensitivity for release from pTOMCAT grid, release times and heights as follows: (a) 17:00-18:00 UTC, 3 March 2007, 0-0.5 km; (b) 17:00-18:00 UTC, 3 March 2007, 1.5-2.0 km; (c) 14:00-15:00 UTC, 3 April 2011,0-0.5 km; and (d) 14:0015:00 UTC, 3 April 2011, 1.5-2.0 km.

\subsection{HDO depletion}

\subsection{1 $\delta$ D-PWV observation}

Figure 12 shows the evolution of $\delta \mathrm{D}$ as a function of PWV during the two cyclone events. The grey dots are 9 -year $\delta \mathrm{D}-$ PWV Bruker 125HR measurements (all data, 2006-2014). The red and blue dots are daily mean $\delta \mathrm{D}-\mathrm{PWV}$ values for the dates indicated. The green dot in Fig. 12a and b represents March (April) mean $\delta$ D-PWV values over all 9 years. Other Rayleigh curves with different phase equilibrium ice-vapour fraction coefficients $\left(\alpha_{\text {e-ice-vapour }}\right)$ are indicated by coloured dashed lines, with Fig. 12a using the $\delta \mathrm{D}-\mathrm{PWV}$ daily mean on 1 March 2007 as the origin and Fig. 12b using the $\delta$ DPWV daily mean on 2 April 2011 as the origin. The dashed green $\left(\alpha_{\text {e-ice-vapour }}=1.198\right)$ and blue $\left(\alpha_{\mathrm{e} \text {-ice-vapour }}=1.228\right)$ Rayleigh curves correspond to condensation processes at temperatures of -30 and $-40^{\circ} \mathrm{C}$ (Merlivat and Nief, 1967). The error bars on the red and blue dots are standard deviations of the $\delta \mathrm{D}-\mathrm{PWV}$ values used to calculate the daily mean.

Figure 12a shows an HDO depletion process from 28 February to 4 March 2007 (red dots), followed by a moistening process from 5 to 6 March (blue dots). The HDO depletion from 2 to 4 March 2007 corresponds to the conden- 

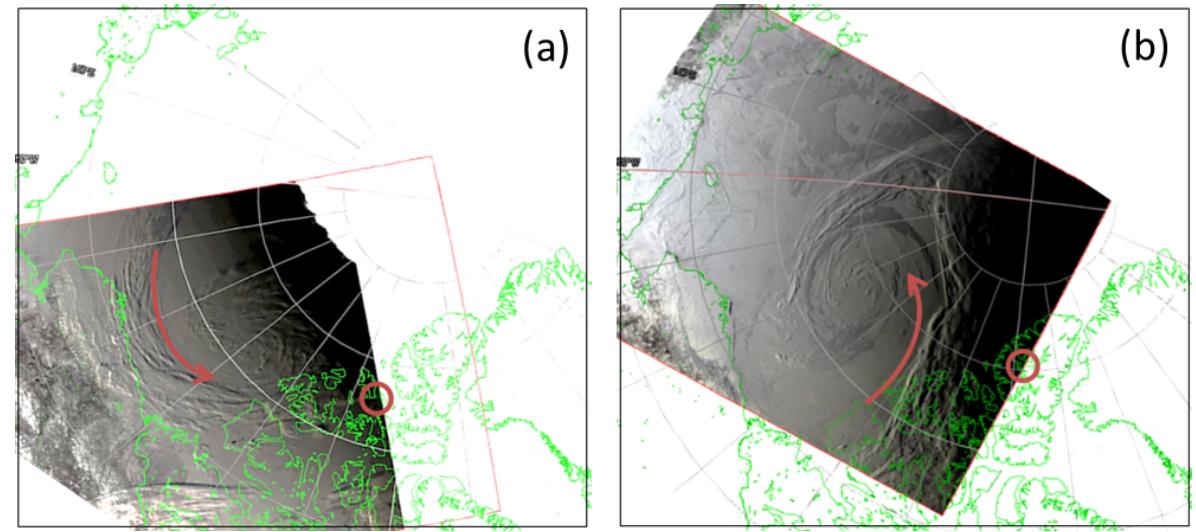

Figure 8. MODIS images showing the cyclones (indicated with arrows) over the Beaufort Sea for the 2007 and 2011 events: (a) 27 February 2007 and (b) 1 April 2011. Eureka is indicated by the red circle on both panels.
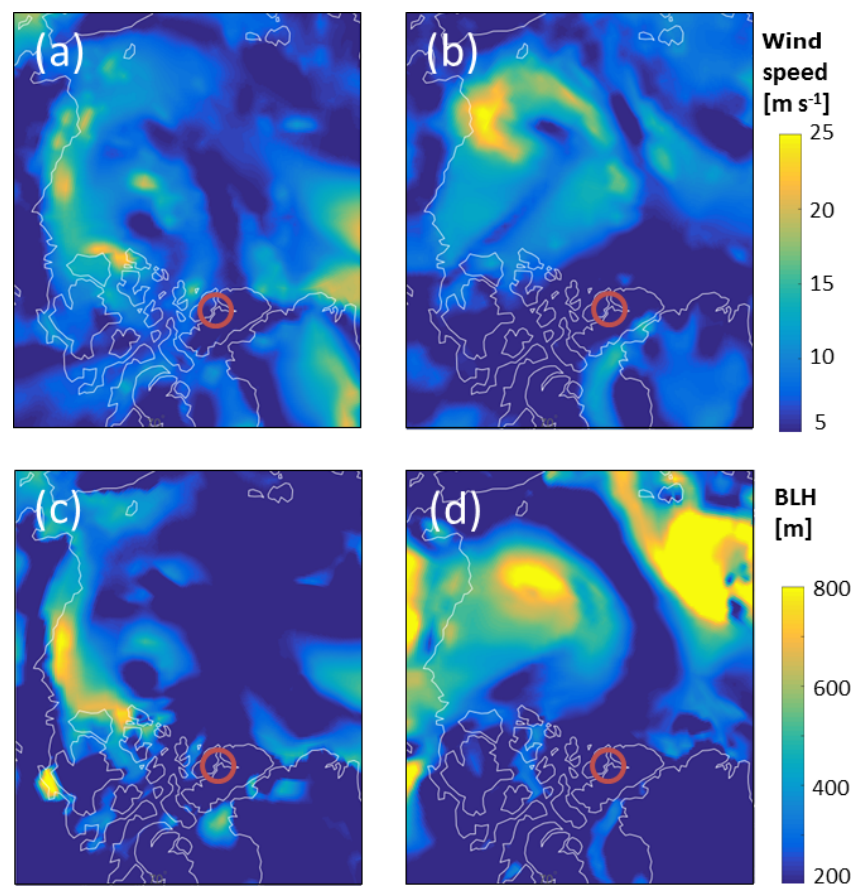

Figure 9. ERA-Interim $10 \mathrm{~m}$ wind gust and boundary layer heights: (a) wind gust on 28 February 2007 00:00 UTC, (b) wind gust on 1 April 2011 00:00 UTC, (c) boundary layer height at the same time as (a), and (d) boundary layer height at the same time as (b). Eureka is indicated by the red circle on each panel. These two dates were selected when the cyclones were fully developed.

sation process in the cyclonic air mass, which was captured by the Rayleigh fractioning model (see the green and blue Rayleigh curves). Tropospheric RH measured by radiosondes is below $75 \%$ from 2 to 4 March 2007, and temperatures in the $0-4 \mathrm{~km}$ cloud layers were -35 to $-45^{\circ} \mathrm{C}$ during the period. Thus, kinetic fractionation due to supersaturation in ice clouds is not applicable for this case. The deviation of the $\delta$ D-PWV pair from Rayleigh curves (green and blue dashed lines) on 3 March 2007 is possibly due to sublimation of HDO-enriched blowing snow. The water vapour sublimation flux from blowing snow is $0.5 \mathrm{~mm}^{-1 a y}{ }^{-1}$, with conditions of $10 \mathrm{~m} \mathrm{~s}^{-1}$ wind speed, $-20^{\circ} \mathrm{C}$ ambient temperature, and $80 \%$ $\mathrm{RH}$. With conditions of $20 \mathrm{~m} \mathrm{~s}^{-1}$ wind speed, $-20^{\circ} \mathrm{C}$ ambient temperature, and $75 \% \mathrm{RH}$, the water vapour sublimation flux from blowing snow can increase to $2.6 \mathrm{~mm} \mathrm{day}^{-1}$. These amounts of water vapour sublimation flux from $\delta \mathrm{D}$-enriched blowing snow are strong enough to affect the atmospheric $\delta \mathrm{D}$ value (since the PWV on 4 March 2007 is only $0.5 \mathrm{~mm}$ ) through mixing. The temporal mixing line method (Keeling, 1958; Miller and Tans, 2003; Noone et al., 2013) can be used to estimate the $\delta \mathrm{D}$ and/or sublimation flux of blowing snow. However, isotopologue measurements for precipitation at the source region (for example, near the Beaufort Sea) are necessary to validate the results and to make meaningful comparison of measured with modelled sublimation flux. In general, more detailed water isotopologue modelling and observations are necessary to further evaluate the blowing-snow HDO evolution.

Figure 12a also shows a remoistening process that started on 5 March (see blue dots), which was due to the cyclonic air mass starting to mix with a different air mass transported from the north. This mixing process is also coincident with the termination of the ODE. As shown in Fig. 11, the shallow surface ODE became weaker on 5 March than that on 3 and 4 March and terminated on 6 to 7 March, as the surface ozone VMR increased from 11 to $15 \mathrm{ppbv}$.

Figure $12 \mathrm{~b}$ shows an HDO depletion process from 1 to 6 April 2011. The depletion process from 2 to 5 April is also deviated from Rayleigh process (green and blue dashed lines) on 3 April (the measured $0-4 \mathrm{~km}$ cloud temperature is -30 to $-35^{\circ} \mathrm{C}$ ). Tropospheric $\mathrm{RH}$ measured by radiosondes is below $80 \%$ from 3 to 5 April 2011. Surface clouds containing ice crystals were observed for the 2011 case (Zhao et al., 2016a), and other meteorological conditions were also similar to the 2007 case. Thus, as with the 2007 event, the 
(a)
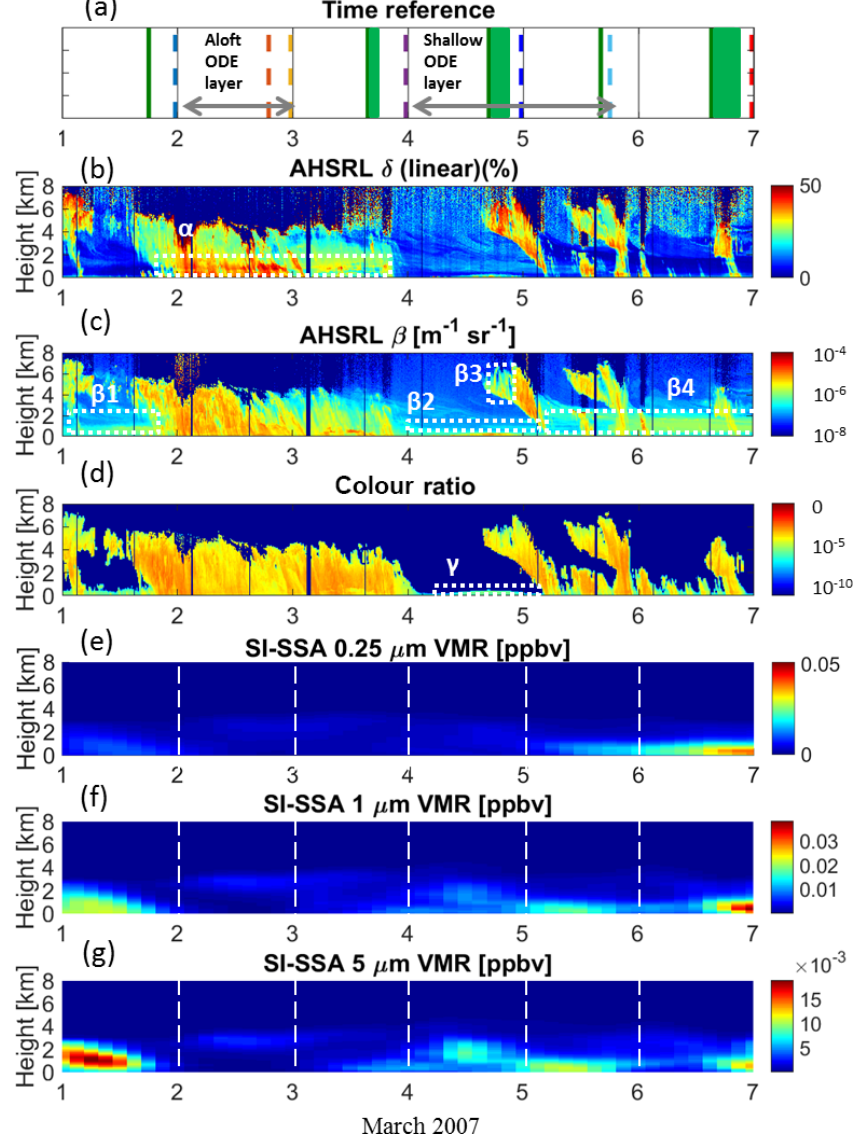

Figure 10. Comparison of lidar (AHSRL) aerosol measurements with pTOMCAT modelled sea-ice sea-salt aerosol (SI-SSA), 0$4 \mathrm{~km}$ over Eureka from 1 to 7 March 2007: (a) time reference for coincident measurements from ozonesondes (indicated by colour dashed lines) and Bruker 125HR (indicated by solid green lines/boxes), (b) lidar linear depolarization, (c) lidar backscatter cross section, (d) colour ratio, (e) pTOMCAT $0.25 \mu \mathrm{m}$ SISS volume mixing ratio, (f) pTOMCAT $1.0 \mu \mathrm{m}$ SISS VMR, and (g) pTOMCAT 5.0 $\mu \mathrm{m}$ SISS VMR. Grey horizontal double-headed arrows in (a) indicate the periods when ozonesondes measured the aloft ozone depletion layer and the shallow depletion layer. White boxes in (b), (c), and (d) indicate detection of the ice cloud $(\alpha)$, aerosol $(\beta 1, \beta 2$, and $\beta 4)$, ice cloud $(\beta 3)$, and ice crystals $(\gamma)$.

sublimation of HDO-enriched blowing snow is possibly the cause of this measured $\delta \mathrm{D}-\mathrm{PWV}$ deviation from Rayleigh process; the measured fractioning result on 3 April 2011 appears to be weaker (less HDO loss) than modelled green and blue Rayleigh fractioning lines.

In general, the $\delta \mathrm{D}-\mathrm{PWV}$ values provide useful information regarding the history of the cyclonic air mass. HDO depletion on 3 March 2007 and 3 April 2011 (during two ODEs) was found to deviate from (weaker than) pure Rayleigh fractionation, suggesting that sublimation likely contributed to the $\delta \mathrm{D}$ evolution.

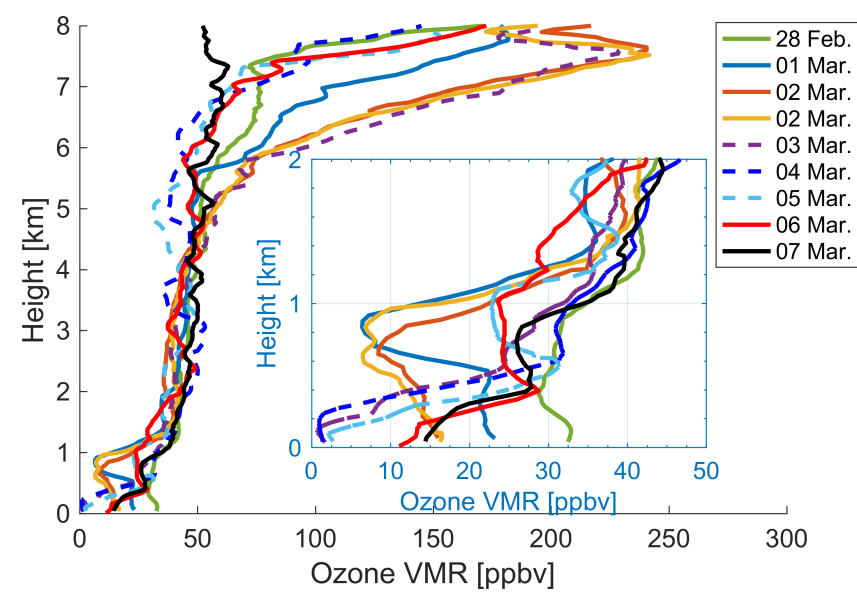

Figure 11. Ozonesonde profiles above Eureka (the inset panel shows 0-2 km) from 28 February to 7 March 2007.
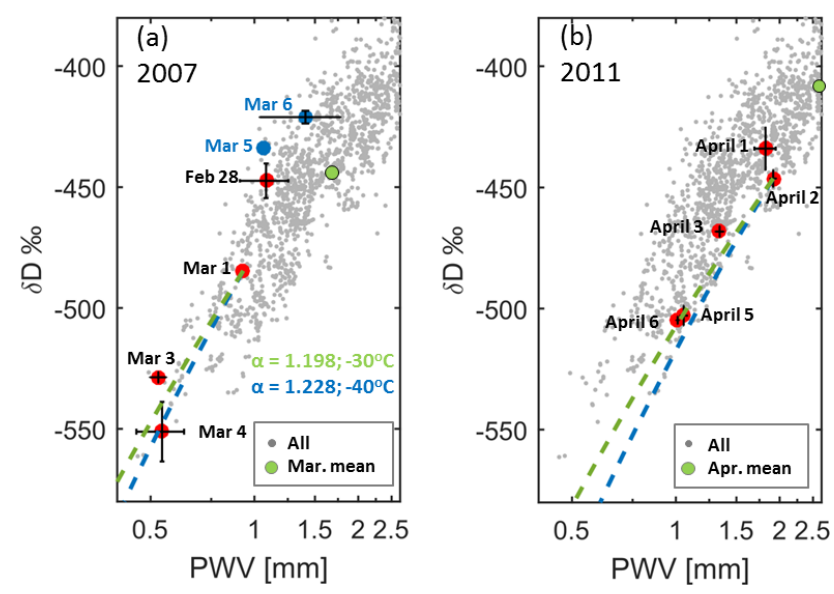

Figure 12. Evolution of $\delta \mathrm{D}$ as a function of PWV (log scale). Grey dots are 9-year (2006-2014) Bruker 125HR $\delta$ D-PWV measurements. Panel (a) shows the 2007 event, with 28 February to 7 March 2007 daily mean $\delta$ D-PWV values shown in red (a depletion process; decrease in both $\delta \mathrm{D}$ and PWV with time) and blue (a remoistening process; increase in both $\delta \mathrm{D}$ and PWV with time) dots. Panel (b) shows the 2011 event, with 1 to 6 April 2011 daily mean $\delta$ D-PWV values shown by red dots. The green dot in $(\mathbf{a}) /(\mathbf{b})$ represents March/April mean values of all 9 years. Rayleigh curves with different fraction coefficients are indicated by coloured dashed lines, with (a) using $\delta$ D-PWV daily mean value on 1 March 2007 as the origin, and (b) using $\delta$ D-PWV daily mean value on 2 April 2011 value as the origin. The error bars are standard deviations of $\delta \mathrm{D}$ PWV values used to calculate the daily mean.

\subsubsection{Influence of the polar vortex}

The previous sections described surface ODEs coincident with the observation of depleted HDO and increased SSA. Derived meteorological products (DMPs), similar to those described by Manney et al. (2007), were calculated using the JETPAC package (Manney et al., 2011) for above Eureka 

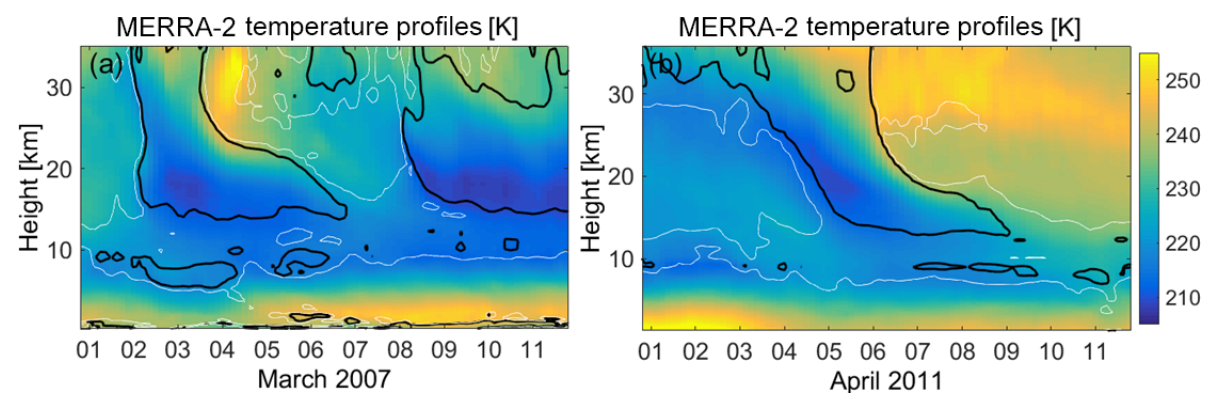

Figure 13. Vertical temperature profiles over Eureka from MERRA-2. The black contour indicates the inner boundaries of the polar vortex determined by $\mathrm{sPV}=1.6 \times 10^{-4} \mathrm{~s}^{-1}$, and the white contour indicates the outer boundaries $\left(\mathrm{sPV}=1.4 \times 10^{-4} \mathrm{~s}^{-1}\right)$.
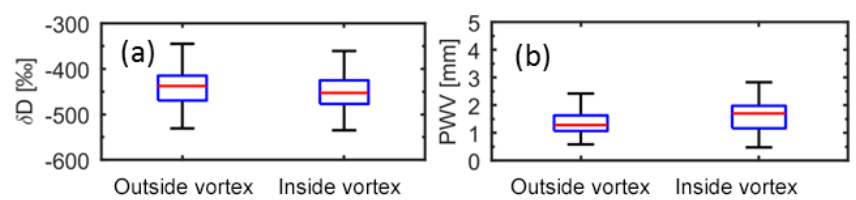

March
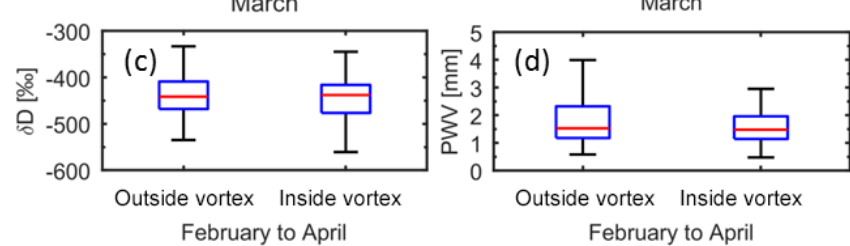

Figure 14. Bruker $125 \mathrm{HR} \delta \mathrm{D}$ and PWV box-and-whisker plots for 9 years of measurements (2006-2014) outside and inside the vortex. Panels (a) and (b) show March $\delta \mathrm{D}$ and PWV measurements, respectively, and (c) and (d) show springtime measurements (from February to April). In each box, the central red line is the median, the edges of the blue box are the 25th and 75th percentiles, and the black whiskers extend to the most extreme data points not considered outliers.

and along the lines of sight of the Bruker instrument (Lindenmaier et al., 2012) using MERRA-2 analysis. Figure 13 shows the MERRA-2 temperature profiles over Eureka with the boundaries of the polar vortex indicated (defined by an sPV value of $1.6 \times 10^{-4} \mathrm{~s}^{-1}$ for the inner edge of the vortex, Manney et al., 2007). Both the 2007 and 2011 events show strong cooling $(210-220 \mathrm{~K})$ in the stratosphere from 15 to $25 \mathrm{~km}$, which is caused by the presence of the stratospheric polar vortex overhead (Manney et al., 2008; Adams et al., 2013). In both cases, the stratospheric vortex and the tropospheric cyclonic low-pressure system were present at the same time. MERRA-2 captured the surface pressure and temperature changes in the polar lows, as seen from the decreased surface temperature in Fig. 13a for 3-4 March 2007 and in Fig. 13b for 5-6 April 2011. MERRA-2 PV maps (not shown here) indicate that the edge of the elongated vortex was over Eureka for both years. Cold stratospheric air masses are more HDO depleted than warm air masses. Since the extremely low $\delta \mathrm{D}$ values measured during these two events were coincident with the presence of the stratospheric vortex, the $\delta \mathrm{D}$ sensitivity in the stratosphere was examined.

The Bruker 125HR water vapour measurements have limited sensitivity in the stratosphere and therefore the $\delta \mathrm{D}$ data should have limited sensitivity to the presence of the polar vortex. We investigated the $\delta \mathrm{D}$ sensitivity to the air mass being inside and outside the stratospheric vortex. Following Manney et al. (2007) and Adams et al. (2012b), sPV values along the lines of sight of the Bruker instrument were interpolated to the $490 \mathrm{~K}$ potential temperature level (lower stratosphere, $\sim 19 \mathrm{~km}$ ), with the inner vortex edge defined by $\mathrm{sPV}_{490 \mathrm{~K}}$ values of $1.6 \times 10^{-4}$. With the $\mathrm{SPV}_{490 \mathrm{~K}}$ values, the Bruker measurements can be categorized into two regimes: inside and outside the polar vortex.

Figure 14 shows the box-and-whisker plots of Bruker $\delta \mathrm{D}$ and PWV data. Figure $14 \mathrm{a}$ and $\mathrm{b}$ show the $\delta \mathrm{D}$ and PWV data in March of all 9 years. The median $\delta \mathrm{D}$ outside the vortex in March is $-438_{-31}^{+23} \%$ ( 75 th to 25 th percentile), while the value inside the vortex is $-453_{-24}^{+28} \%$. Thus, statistically, there is no significant difference of $\delta \mathrm{D}$ in these two regimes. In Fig. 14c and d, the period is expanded to all spring measurements (from February to April, by which time the stratospheric vortex has broken up), and these panels also confirmed that the Bruker $\delta \mathrm{D}$ and PWV data are not sensitive to the presence of the polar vortex. Moreover, no evidence was found in the ozonesonde ozone and radiosonde $\mathrm{RH}$ measurements to indicate the existence of a stratospheric intrusion, which could cause low HDO. Thus, to summarize, this sensitivity test and observations indicate that the extremely low $\delta \mathrm{D}$ measured during the two events studied here were caused by tropospheric HDO depletion.

\section{Conclusions}

Data from six instruments and four models were used to investigate Arctic ODEs. Using the TCO, tropopause height, and $\delta \mathrm{D}$ data, two similar cyclone events that show both depleted surface ozone and HDO at Eureka were identified from the 9-year dataset: in March 2007 and April 2011. The FLEXPART particle dispersion model was used to simulate 
air mass transport. The aerosol tracers released in all backwards simulations show sensitivity to the Beaufort Sea region, and the plumes revealed the structure of the cyclones. The ERA-Interim data show that the wind speed in the cyclone increased to 20 and $24 \mathrm{~m} \mathrm{~s}^{-1}$ for the 2007 and 2011 cases, respectively, and the boundary layer heights increased to 710 and $800 \mathrm{~m}$, respectively.

In general, the ground-based observations show good agreement with modelled ozone and $\mathrm{BrO}$ data. One key result is that the modelled $\mathrm{BrO}$ and ozone in the near-surface layer are quite sensitive to the snow salinity. Newly incorporated surface snow salinity data increased the modelled $\mathrm{BrO}$ concentration above Eureka to agree with our previous measurements for the 2011 event (Zhao et al., 2016a). This is due to the reduced bromine flux from the source region, which, as a result, reduced the depletion of ozone along the trajectory and preserved a higher concentration of bromine oxide. This result supports the conclusion of that study that during a strong surface ODE (ozone VMR $<1$ ppbv), BrO concentration can be significantly controlled by the ozone concentration.

Modelled blowing-snow SSA was compared with lidar/radar measurements showing that pTOMCAT SI-SSA data captured some features of the increased aerosol for the 2007 and 2011 events. For the 2007 event, the lidar and radar observed ice cloud (vapour and ice crystals) from 700 to $1000 \mathrm{~m}$ height (from the end of 1 to $3 \mathrm{March}$ ), which is coincident with an aloft ozone depletion layer having the greatest ozone depletion (to $7 \mathrm{ppbv}$ ) at $870 \mathrm{~m}$. However, pTOMCAT and UKCA both failed to reproduce this feature in their modelled ozone profiles. The pTOMCAT results show that there was almost no modelled SI-SSA during that period, indicating limitations in the model simulation of aerosol and that further investigation is needed, e.g., into the production and deposition mechanisms of SI-SSA.

The 2007 lidar/radar observations also reveal deposition (falling snow and ice crystals) from this ice cloud at Eureka. Thus, the following shallow surface ODE (0 to $200 \mathrm{~m}$ ) on 4 and 5 March was likely due to the deposition of bromineenriched particles onto the local snowpack. The detailed vertical structure of ice clouds, ice crystal, and aerosol layers obtained for the 2007 event could be used in future bromine modelling comparisons.

HDO depletion observed during these two blowing-snow ODEs is found to be weaker than pure Rayleigh fractionation. The evolution of $\delta \mathrm{D}-\mathrm{PWV}$ was used to distinguish cyclone-originating air masses from non-cyclone-originating air masses, indicating that the termination of the shallow surface ODE is due to mixing with a different air mass. Although the edge of the stratospheric polar vortex was found over Eureka during those periods, no evidence was found that the low $\delta \mathrm{D}$ value was caused by the polar vortex or stratospheric intrusions. This work thus provides evidence of a blowing-snow sublimation process, which is a key step in producing bromine-enriched SSA. In general, this work im- proved our understanding of ODE processes by combining a variety of measurements with atmospheric models, and it facilitated both improved modelling of the atmosphere and the interpretation of the measurements.

Data availability. The PEARL 125HR FTIR v2015 water vapour dataset is described in Barthlott et al. (2017) and is available at: https://doi.org/10.5281/zenodo.48902 and ftp://ftp.cpc. ncep.noaa.gov/ndacc/MUSICA/. AHSRL and MMCR data are available from: http://hsrl.ssec.wisc.edu/. Brewer and ozonesonde data are available from the World Ozone and UV Data Centre (https://doi.org/10.14287/10000001). Any additional data may be obtained from Xiaoyi Zhao (xizhao@atmosp.physics.utoronto.ca). The FLEXPART model is available at: https://flexpart.eu/. The meteorological data products were obtained from ECMWF, GMAO, and NCEP. MODIS data were obtained from: http://modis.gsfc. nasa.gov/ (false-colour images from SwathViewer, http://sv.gina. alaska.edu/).

Competing interests. The authors declare that they have no conflict of interest.

Acknowledgements. CANDAC/PEARL funding partners are the Arctic Research Infrastructure Fund, Atlantic Innovation Fund/Nova Scotia Research Innovation Trust, Canadian Foundation for Climate and Atmospheric Science, Canada Foundation for Innovation, Canadian Space Agency (CSA), Environment and Climate Change Canada (ECCC), Government of Canada International Polar Year, Natural Sciences and Engineering Research Council (NSERC), Ontario Innovation Trust, Ontario Research Fund, Indian and Northern Affairs Canada, and the Polar Continental Shelf Program. The spring 2006-2014 measurements were also supported by the Canadian Arctic ACE/OSIRIS Validation Campaigns funded by CSA, ECCC, NSERC, the Northern Scientific Training Program, and the Centre for Global Change Science. This work also received funding from the NSERC CREATE Training Program in Arctic Atmospheric Science and the NSERC-supported Probing Atmosphere in the High Arctic (PAHA) project. We thank CANDAC/PEARL/PAHA PI James Drummond, ACE/OSIRIS Validation Campaign PI Kaley Walker, PEARL Site Manager Pierre Fogal, the CANDAC operators, and the staff at ECCC's Eureka weather station for their contributions to data acquisition and logistical and on-site support. We thank Vitali Fioletov and David Tarasick from ECCC for providing Brewer and ozonesonde data. We thank Frederick Michel from Carleton University and Xiahong Feng from Dartmouth College for providing Eureka isotopologue precipitation data. This work has also benefitted from discussions with Jonathan Abbatt and Dylan Jones at the University of Toronto. The MUSICA NDACC/FTIR retrievals have been made in the context of the project MUSICA, which was funded by the European Research Council under the European Community's Seventh Framework Programme (FP7/2007-2013)/ERC grant agreement no. 256961. MERRA-2 work at the Jet Propulsion Laboratory, California Institute of Technology was done under contract with the National Aeronautics and Space Administration. 
Edited by: Andreas Engel

Reviewed by: two anonymous referees

\section{References}

Abbatt, J. P. D., Thomas, J. L., Abrahamsson, K., Boxe, C., Granfors, A., Jones, A. E., King, M. D., Saiz-Lopez, A., Shepson, P. B., Sodeau, J., Toohey, D. W., Toubin, C., von Glasow, R., Wren, S. N., and Yang, X.: Halogen activation via interactions with environmental ice and snow in the polar lower troposphere and other regions, Atmos. Chem. Phys., 12, 6237-6271, https://doi.org/10.5194/acp-12-6237-2012, 2012.

Adams, C., Strong, K., Batchelor, R. L., Bernath, P. F., Brohede, S., Boone, C., Degenstein, D., Daffer, W. H., Drummond, J. R., Fogal, P. F., Farahani, E., Fayt, C., Fraser, A., Goutail, F., Hendrick, F., Kolonjari, F., Lindenmaier, R., Manney, G., McElroy, C. T., McLinden, C. A., Mendonca, J., Park, J. H., Pavlovic, B., Pazmino, A., Roth, C., Savastiouk, V., Walker, K. A., Weaver, D., and Zhao, X.: Validation of ACE and OSIRIS ozone and $\mathrm{NO}_{2}$ measurements using ground-based instruments at $80^{\circ} \mathrm{N}$, Atmos. Meas. Tech., 5, 927-953, https://doi.org/10.5194/amt-5927-2012, 2012a.

Adams, C., Strong, K., Zhao, X., Bassford, M. R., Chipperfield, M. P., Daffer, W., Drummond, J. R., Farahani, E. E., Feng, W., Fraser, A., Goutail, F., Manney, G., McLinden, C. A., Pazmino, A., Rex, M., and Walker, K. A.: Severe 2011 ozone depletion assessed with 11 years of ozone, $\mathrm{NO}_{2}$, and $\mathrm{OClO}$ measurements at $80^{\circ} \mathrm{N}$, Geophys. Res. Lett., 39, L05806, https://doi.org/10.1029/2011g1050478, 2012b.

Adams, C., Strong, K., Zhao, X., Bourassa, A. E., Daffer, W. H., Degenstein, D., Drummond, J. R., Farahani, E. E., Fraser, A., Lloyd, N. D., Manney, G. L., McLinden, C. A., Rex, M., Roth, C., Strahan, S. E., Walker, K. A., and Wohltmann, I.: The spring 2011 final stratospheric warming above Eureka: anomalous dynamics and chemistry, Atmos. Chem. Phys., 13, 611-624, https://doi.org/10.5194/acp-13-611-2013, 2013.

Barrie, L. A., Bottenheim, J. W., Schnell, R. C., Crutzen, P. J., and Rasmussen, R. A.: Ozone destruction and photochemicalreactions at polar sunrise in the lower Arctic atmosphere, Nature, 334, 138-141, 1988.

Barthlott, S., Schneider, M., Hase, F., Blumenstock, T., Kiel, M., Dubravica, D., García, O. E., Sepúlveda, E., Mengistu Tsidu, G., Takele Kenea, S., Grutter, M., Plaza-Medina, E. F., Stremme, W., Strong, K., Weaver, D., Palm, M., Warneke, T., Notholt, J., Mahieu, E., Servais, C., Jones, N., Griffith, D. W. T., Smale, D., and Robinson, J.: Tropospheric water vapour isotopologue data $\left(\mathrm{H}_{2}^{16} \mathrm{O}, \mathrm{H}_{2}^{18} \mathrm{O}\right.$, and $\left.\mathrm{HD}^{16} \mathrm{O}\right)$ as obtained from NDACC/FTIR solar absorption spectra, Earth Syst. Sci. Data, 9, 15-29, https://doi.org/10.5194/essd-9-15-2017, 2017.

Batchelor, R. L., Strong, K., Lindenmaier, R., Mittermeier, R. L., Fast, H., Drummond, J. R., and Fogal, P. F.: A new Bruker IFS 125HR FTIR spectrometer for the Polar Environment Atmospheric Research Laboratory at Eureka, Nunavut, Canada: measurements and comparison with the existing Bomem DA8 spectrometer, J. Atmos. Ocean. Tech., 26, 1328-1340, 2009.

Begoin, M., Richter, A., Weber, M., Kaleschke, L., Tian-Kunze, X., Stohl, A., Theys, N., and Burrows, J. P.: Satellite observations of long range transport of a large $\mathrm{BrO}$ plume in the Arctic, At- mos. Chem. Phys., 10, 6515-6526, https://doi.org/10.5194/acp10-6515-2010, 2010.

Blechschmidt, A.-M., Richter, A., Burrows, J. P., Kaleschke, L., Strong, K., Theys, N., Weber, M., Zhao, X., and Zien, A.: An exemplary case of a bromine explosion event linked to cyclone development in the Arctic, Atmos. Chem. Phys., 16, 1773-1788, https://doi.org/10.5194/acp-16-1773-2016, 2016.

Blossey, P. N., Kuang, Z., and Romps, D. M.: Isotopic composition of water in the tropical tropopause layer in cloud-resolving simulations of an idealized tropical circulation, J. Geophys. Res., 115, D24309, https://doi.org/10.1029/2010jd014554, 2010.

Bosilovich, M. G., Lucchesi, R., and Suarez, M.: MERRA-2: File Specification, GMAO Office Note No. 9 (Version 1.1), NASA, Global Modelling and Assimilation Office, Maryland, USA, 73 pp., available from: https:/gmao.gsfc.nasa.gov/pubs/ docs/Bosilovich785.pdf (last access: 15 December 2017), 2016.

Bottenheim, J. W., Gallant, A. G., and Brice, K. A.: Measurements of $\mathrm{NO}_{y}$ species and $\mathrm{O}_{3}$ at $82^{\circ} \mathrm{N}$ latitude, Geophys. Res. Lett., 13, 113-116, https://doi.org/10.1029/GL013i002p00113, 1986.

Bourdages, L., Duck, T. J., Lesins, G., Drummond, J. R., and Eloranta, E. W.: Physical properties of High Arctic tropospheric particles during winter, Atmos. Chem. Phys., 9, 6881-6897, https://doi.org/10.5194/acp-9-6881-2009, 2009.

Braesicke, P., Keeble, J., Yang, X., Stiller, G., Kellmann, S., Abraham, N. L., Archibald, A., Telford, P., and Pyle, J. A.: Circulation anomalies in the Southern Hemisphere and ozone changes, Atmos. Chem. Phys., 13, 10677-10688, https://doi.org/10.5194/acp-13-10677-2013, 2013.

Calvert, J. G. and Lindberg, S. E.: Potential influence of iodinecontaining compounds on the chemistry of the troposphere in the polar spring, I. Ozone depletion, Atmos. Environ., 38, 50875104, 2004a.

Calvert, J. G. and Lindberg, S. E.: The potential influence of iodinecontaining compounds on the chemistry of the troposphere in the polar spring. II. Mercury depletion, Atmos. Environ., 38, 51055116, https://doi.org/10.1016/j.atmosenv.2004.05.050, 2004b.

Calvert, J. G., Orlando, J. J., Stockwell, W. R., and Wallington, T. J.: The Mechanisms of Reactions Influencing Atmospheric Ozone, Oxford University Press, USA, 2015.

Cavalieri, D. J. and Parkinson, C. L.: Arctic sea ice variability and trends, 1979-2010, The Cryosphere, 6, 881-889, https://doi.org/10.5194/tc-6-881-2012, 2012.

Craig, H.: Standard for reporting concentrations of deuterium and oxygen-18 in natural waters, Science, 133, 1833-1834, 1961.

Dee, D. P., Uppala, S. M., Simmons, A. J., Berrisford, P., Poli, P., Kobayashi, S., Andrae, U., Balmaseda, M. A., Balsamo, G., Bauer, P., Bechtold, P., Beljaars, A. C. M., van de Berg, L., Bidlot, J., Bormann, N., Delsol, C., Dragani, R., Fuentes, M., Geer, A. J., Haimberger, L., Healy, S. B., Hersbach, H., Hólm, E. V., Isaksen, L., Kållberg, P., Köhler, M., Matricardi, M., McNally, A. P., Monge-Sanz, B. M., Morcrette, J. J., Park, B. K., Peubey, C., de Rosnay, P., Tavolato, C., Thépaut, J. N., and Vitart, F.: The ERA-Interim reanalysis: configuration and performance of the data assimilation system, Q. J. Roy. Meteor. Soc., 137, 553-597, https://doi.org/10.1002/qj.828, 2011.

Déry, S. J. and Yau, M.: A bulk blowing snow model, Bound.-Lay. Meteorol., 93, 237-251, 1999. 
Déry, S. J. and Yau, M.: Simulation of blowing snow in the Canadian Arctic using a double-moment model, Bound.-Lay. Meteorol., 99, 297-316, 2001.

Dunkerton, T. J. and Delisi, D. P.: Evolution of Potential Vorticity in the Winter Stratosphere of JanuaryFebruary 1979, J. Geophys. Res., 91, 1199-1208, https://doi.org/10.1029/JD091iD01p01199, 1986.

Ehhalt, D., Knott, K., Nagel, J., and Vogel, J.: Deuterium and oxygen 18 in rain water, J. Geophys. Res., 68, 3775-3780, 1963.

Fioletov, V., Kerr, J., Wardle, D., and Wu, E.: Correction of stray light for the Brewer single monochromator, Proceedings of the Quadrennial Ozone Symposium, Japan, 3-8 July 2000.

Fioletov, V., Kerr, J., McElroy, C., Wardle, D., Savastiouk, V., and Grajnar, T.: The Brewer reference triad, Geophys. Res. Lett., 32, L20805, https://doi.org/10.1029/2005GL024244, 2005.

Fogal, P. F., LeBlanc, L. M., and Drummond, J. R.: The Polar Environment Atmospheric Research Laboratory (PEARL): Sounding the Atmosphere at 80 $\mathrm{N}$, Arctic, 66, 337-386, 2013.

Frieß, U., Hollwedel, J., König-Langlo, G., Wagner, T., and Platt, U.: Dynamics and chemistry of tropospheric bromine explosion events in the Antarctic coastal region, J. Geophys. Res., 109, D06305, https://doi.org/10.1029/2003jd004133, 2004.

Frieß, U., Sihler, H., Sander, R., Pöhler, D., Yilmaz, S., and Platt, U.: The vertical distribution of $\mathrm{BrO}$ and aerosols in the Arctic: Measurements by active and passive differential optical absorption spectroscopy, J. Geophys. Res., 116, D00R04, https://doi.org/10.1029/2011jd015938, 2011.

Fujiwara, M., Wright, J. S., Manney, G. L., Gray, L. J., Anstey, J., Birner, T., Davis, S., Gerber, E. P., Harvey, V. L., Hegglin, M. I., Homeyer, C. R., Knox, J. A., Krüger, K., Lambert, A., Long, C. S., Martineau, P., Molod, A., Monge-Sanz, B. M., Santee, M. L., Tegtmeier, S., Chabrillat, S., Tan, D. G. H., Jackson, D. R., Polavarapu, S., Compo, G. P., Dragani, R., Ebisuzaki, W., Harada, Y., Kobayashi, C., McCarty, W., Onogi, K., Pawson, S., Simmons, A., Wargan, K., Whitaker, J. S., and Zou, C.-Z.: Introduction to the SPARC Reanalysis Intercomparison Project (S-RIP) and overview of the reanalysis systems, Atmos. Chem. Phys., 17, 1417-1452, https://doi.org/10.5194/acp17-1417-2017, 2017.

Gilman, J. B., Burkhart, J. F., Lerner, B. M., Williams, E. J., Kuster, W. C., Goldan, P. D., Murphy, P. C., Warneke, C., Fowler, C., Montzka, S. A., Miller, B. R., Miller, L., Oltmans, S. J., Ryerson, T. B., Cooper, O. R., Stohl, A., and de Gouw, J. A.: Ozone variability and halogen oxidation within the Arctic and sub-Arctic springtime boundary layer, Atmos. Chem. Phys., 10, 1022310236, https://doi.org/10.5194/acp-10-10223-2010, 2010.

Global Modeling and Assimilation Office (GMAO), MERRA2 inst3_3d_asm_Nv: 3d, 3-Hourly,Instantaneous, ModelLevel, Assimilation, Assimilated Meteorological Fields V5.12.4, Greenbelt, MD, USA, Goddard Earth Sciences Data and Information Services Center (GES DISC), https://doi.org/10.5067/WWQSXQ8IVFW8 (last access: 1 April 2016), 2015.

Heintzenberg, J., Covert, D., and Van Dingenen, R.: Size distribution and chemical composition of marine aerosols: a compilation and review, Tellus B, 52, 1104-1122, 2000.

Hoyle, C. R., Marécal, V., Russo, M. R., Allen, G., Arteta, J., Chemel, C., Chipperfield, M. P., D’Amato, F., Dessens, O., Feng, W., Hamilton, J. F., Harris, N. R. P., Hosking, J. S., Lewis, A. C.,
Morgenstern, O., Peter, T., Pyle, J. A., Reddmann, T., Richards, N. A. D., Telford, P. J., Tian, W., Viciani, S., Volz-Thomas, A., Wild, O., Yang, X., and Zeng, G.: Representation of tropical deep convection in atmospheric models - Part 2: Tracer transport, Atmos. Chem. Phys., 11, 8103-8131, https://doi.org/10.5194/acp11-8103-2011, 2011.

Johnson, C., Mann, G., Bellouin, N., and Dalvi, M.: Comparison between UKCAMODE and CLASSIC aerosol schemes in HadGEM3, Integrated Climate Programme MOHC Report M3.2 to DECC, March 2010, Technical Report, Met Office, 24 pp., 2010.

Jones, A. E., Anderson, P. S., Begoin, M., Brough, N., Hutterli, M. A., Marshall, G. J., Richter, A., Roscoe, H. K., and Wolff, E. W.: BrO, blizzards, and drivers of polar tropospheric ozone depletion events, Atmos. Chem. Phys., 9, 4639-4652, https://doi.org/10.5194/acp-9-4639-2009, 2009.

Jouzel, J. and Merlivat, L.: Deuterium and oxygen 18 in precipitation: Modeling of the isotopic effects during snow formation, J. Geophys. Res., 89, 11749-11757, 1984.

Keeling, C. D.: The concentration and isotopic abundances of atmospheric carbon dioxide in rural areas, Geochim. Cosmochim. Ac., 13, 322-334, 1958.

Kerr, J.: New methodology for deriving total ozone and other atmospheric variables from Brewer spectrophotometer direct sun spectra, J. Geophys. Res., 107, D234731, https://doi.org/10.1029/2001JD001227, 2002.

Kerr, J., McElroy, C., and Olafson, R.: Measurements of ozone with the Brewer ozone spectrophotometer, Proceedings of the Quadrennial Ozone Symposium, Boulder, 1981, 74-79, 1981.

Kerzenmacher, T. E., Walker, K. A., Strong, K., Berman, R., Bernath, P. F., Boone, C. D., Drummond, J. R., Fast, H., Fraser, A., and MacQuarrie, K.: Measurements of $\mathrm{O}_{3}$, $\mathrm{NO}_{2}$ and temperature during the 2004 Canadian Arctic ACE Validation Campaign, Geophys. Res. Lett., 32, L16S07, https://doi.org/10.1029/2005GL023032, 2005.

Legrand, M., Yang, X., Preunkert, S., and Theys, N.: Year-round records of sea salt, gaseous, and particulate inorganic bromine in the atmospheric boundary layer at coastal (Dumont d'Urville) and central (Concordia) East Antarctic sites, J. Geophys. Res. 121, 997-1023, https://doi.org/10.1002/2015jd024066, 2016.

Lehrer, E., Hönninger, G., and Platt, U.: A one dimensional model study of the mechanism of halogen liberation and vertical transport in the polar troposphere, Atmos. Chem. Phys., 4, 2427 2440, https://doi.org/10.5194/acp-4-2427-2004, 2004.

Levine, J., Yang, X., Jones, A., and Wolff, E.: Sea salt as an ice core proxy for past sea ice extent: A processbased model study, J. Geophys. Res., 119, 5737-5756, https://doi.org/10.1002/2013JD020925, 2014.

Lewis, E. R. and Schwartz, S. E.: Sea salt aerosol production: mechanisms, methods, measurements, and models-A critical review, American Geophysical Union, USA, 413 pp., 2004.

Lindenmaier, R., Strong, K., Batchelor, R. L., Chipperfield, M. P., Daffer, W. H., Drummond, J. R., Duck, T. J., Fast, H., Feng, W., Fogal, P. F., Kolonjari, F., Manney, G. L., Manson, A., Meek, C., Mittermeier, R. L., Nott, G. J., Perro, C., and Walker, K. A.: Unusually low ozone, $\mathrm{HCl}$, and $\mathrm{HNO}_{3}$ column measurements at Eureka, Canada during winter/spring 2011, Atmos. Chem. Phys., 12, 3821-3835, https://doi.org/10.5194/acp12-3821-2012, 2012. 
Lutsch, E., Dammers, E., Conway, S., and Strong, K.: Long-range transport of $\mathrm{NH}_{3}, \mathrm{CO}, \mathrm{HCN}$, and $\mathrm{C}_{2} \mathrm{H}_{6}$ from the 2014 Canadian Wildfires, Geophys. Res. Lett., 43, 8286-8297, 2016.

Manney, G. L., Zurek, R. W., Gelman, M. E., Miller, A. J., and Nagatani, R.: The anomalous Arctic lower stratospheric polar vortex of 1992-1993, Geophys. Res. Lett., 21, 2405-2408, https://doi.org/10.1029/94g102368, 1994.

Manney, G. L., Daffer, W. H., Zawodny, J. M., Bernath, P. F., Hoppel, K. W., Walker, K. A., Knosp, B. W., Boone, C., Remsberg, E. E., Santee, M. L., Harvey, V. L., Pawson, S., Jackson, D. R., Deaver, L., McElroy, C. T., McLinden, C. A., Drummond, J. R., Pumphrey, H. C., Lambert, A., Schwartz, M. J., Froidevaux, L., McLeod, S., Takacs, L. L., Suarez, M. J., Trepte, C. R., Cuddy, D. C., Livesey, N. J., Harwood, R. S., and Waters, J. W.: Solar occultation satellite data and derived meteorological products: Sampling issues and comparisons with Aura Microwave Limb Sounder, J. Geophys. Res., 112, D24S50, https://doi.org/10.1029/2007jd008709, 2007.

Manney, G. L., Daffer, W. H., Strawbridge, K. B., Walker, K. A., Boone, C. D., Bernath, P. F., Kerzenmacher, T., Schwartz, M. J., Strong, K., Sica, R. J., Krüger, K., Pumphrey, H. C., Lambert, A., Santee, M. L., Livesey, N. J., Remsberg, E. E., Mlynczak, M. G., and Russell Iii, J. R.: The high Arctic in extreme winters: vortex, temperature, and MLS and ACE-FTS trace gas evolution, Atmos. Chem. Phys., 8, 505-522, https://doi.org/10.5194/acp-8505-2008, 2008.

Manney, G. L., Hegglin, M. I., Daffer, W. H., Santee, M. L., Ray, E. A., Pawson, S., Schwartz, M. J., Boone, C. D., Froidevaux, L., Livesey, N. J., Read, W. G., and Walker, K. A.: Jet characterization in the upper troposphere/lower stratosphere (UTLS): applications to climatology and transport studies, Atmos. Chem. Phys., 11, 6115-6137, https://doi.org/10.5194/acp11-6115-2011, 2011.

May, N., Quinn, P., McNamara, S., and Pratt, K.: Multiyear study of the dependence of sea salt aerosol on wind speed and sea ice conditions in the coastal Arctic, J. Geophys. Res., 121, 92089219, 2016.

McElroy, C. T., McLinden, C. A., and McConnell, J. C.: Evidence for bromine monoxide in the free troposphere during the Arctic polar sunrise, Nature, 397, 338-341, 1999.

Merlivat, L. and Nief, G.: Fractionnement isotopique lors des changements d'état solide-vapeur et liquide-vapeur de l'eau à des températures inférieures à $0^{\circ} \mathrm{C}$, Tellus, 19, 122-127, 1967.

Miller, J. B. and Tans, P. P.: Calculating isotopic fractionation from atmospheric measurements at various scales, Tellus B, 55, 207214, 2003.

Morgenstern, O., Braesicke, P., O'Connor, F. M., Bushell, A. C., Johnson, C. E., Osprey, S. M., and Pyle, J. A.: Evaluation of the new UKCA climate-composition model Part 1: The stratosphere, Geosci. Model Dev., 2, 43-57, https://doi.org/10.5194/gmd-2-43-2009, 2009.

Moyer, E. J., Irion, F. W., Yung, Y. L., and Gunson, M. R.: ATMOS stratospheric deuterated water and implications for tropospherestratosphere transport, Geophys. Res. Lett., 23, 2385-2388, 1996.

Nilsson, E., Rannik, Ü., Swietlicki, E., Leck, C., Aalto, P. P., Zhou, J., and Norman, M.: Turbulent aerosol fluxes over the Arctic Ocean: 2. Wind-driven sources from the sea, J. Geophys. Res., 106, 32139-32154, 2001.
Noone, D.: Pairing measurements of the water vapor isotope ratio with humidity to deduce atmospheric moistening and dehydration in the tropical midtroposphere, J. Clim., 25, 4476-4494, 2012.

Noone, D., Risi, C., Bailey, A., Berkelhammer, M., Brown, D. P., Buenning, N., Gregory, S., Nusbaumer, J., Schneider, D., Sykes, J., Vanderwende, B., Wong, J., Meillier, Y., and Wolfe, D.: Determining water sources in the boundary layer from tall tower profiles of water vapor and surface water isotope ratios after a snowstorm in Colorado, Atmos. Chem. Phys., 13, 1607-1623, https://doi.org/10.5194/acp-13-1607-2013, 2013.

O'Connor, F., Carver, G., Savage, N., Pyle, J., Methven, J., Arnold, S., Dewey, K., and Kent, J.: Comparison and visualisation of high-resolution transport modelling with aircraft measurements, Atmos. Sci. Lett., 6, 164-170, 2005.

Pratt, K. A., Custard, K. D., Shepson, P. B., Douglas, T. A., Pohler, D., General, S., Zielcke, J., Simpson, W. R., Platt, U., Tanner, D. J., Gregory Huey, L., Carlsen, M., and Stirm, B. H.: Photochemical production of molecular bromine in Arctic surface snowpacks, Nat. Geosci., 6, 351-356, https://doi.org/10.1038/ngeo1779, 2013.

Rannik, U.: Turbulent aerosol fluxes over the Arctic Ocean, 1. Dry deposition over sea and pack ice, J. Geophys. Res., 106, 132125132137, 2001.

Rayleigh, L. and Ramsay, W.: Argon, a New Constituent of the Atmosphere, P. R. Soc. London, 57, 265-287, 1894.

Rayner, N., Parker, D. E., Horton, E., Folland, C., Alexander, L., Rowell, D., Kent, E., and Kaplan, A.: Global analyses of sea surface temperature, sea ice, and night marine air temperature since the late nineteenth century, J. Geophys. Res., 108, D144407, https://doi.org/10.1029/2002JD002670, 2003.

Reader, M. and McFarlane, N.: Sea-salt aerosol distribution during the Last Glacial Maximum and its implications for mineral dust, J. Geophys. Res., 108, D84253, https://doi.org/10.1029/2002JD002063, 2003.

Rhodes, R. H., Yang, X., Wolff, E. W., McConnell, J. R., and Frey, M. M.: Sea ice as a source of sea salt aerosol to Greenland ice cores: a model-based study, Atmos. Chem. Phys., 17, 94179433, https://doi.org/10.5194/acp-17-9417-2017, 2017.

Rozanski, K., Araguas-Araguas, L., and Gonfiantini, R.: Relation between long-term trends of oxygen-18 isotope composition of precipitation and climate, Science, 258, 981-985, 1992.

Russo, M. R., Marécal, V., Hoyle, C. R., Arteta, J., Chemel, C., Chipperfield, M. P., Dessens, O., Feng, W., Hosking, J. S., Telford, P. J., Wild, O., Yang, X., and Pyle, J. A.: Representation of tropical deep convection in atmospheric models - Part 1: Meteorology and comparison with satellite observations, Atmos. Chem. Phys., 11, 2765-2786, https://doi.org/10.5194/acp11-2765-2011, 2011.

Ruti, P., Williams, J., Hourdin, F., Guichard, F., Boone, A., Van Velthoven, P., Favot, F., Musat, I., Rummukainen, M., and Domínguez, M.: The West African climate system: a review of the AMMA model inter-comparison initiatives, Atmos. Sci. Lett., 12, 116-122, 2011.

Saha, S., Moorthi, S., Wu, X., Wang, J., Nadiga, S., Tripp, P., Behringer, D., Hou, Y.-T., Chuang, H.-y., Iredell, M., Ek, M., Meng, J., Yang, R., Mendez, M. P., Dool, H. v. d., Zhang, Q., Wang, W., Chen, M., and Becker, E.: The NCEP Cli- 
mate Forecast System Version 2, J. Clim., 27, 2185-2208, https://doi.org/10.1175/jcli-d-12-00823.1, 2014.

Sander, R., Keene, W. C., Pszenny, A. A. P., Arimoto, R., Ayers, G. P., Baboukas, E., Cainey, J. M., Crutzen, P. J., Duce, R. A., Hönninger, G., Huebert, B. J., Maenhaut, W., Mihalopoulos, N., Turekian, V. C., and Van Dingenen, R.: Inorganic bromine in the marine boundary layer: a critical review, Atmos. Chem. Phys., 3, 1301-1336, https://doi.org/10.5194/acp-3-1301-2003, 2003.

Schneider, M., Wiegele, A., Barthlott, S., González, Y., Christner, E., Dyroff, C., García, O. E., Hase, F., Blumenstock, T., Sepúlveda, E., Mengistu Tsidu, G., Takele Kenea, S., Rodríguez, S., and Andrey, J.: Accomplishments of the MUSICA project to provide accurate, long-term, global and high-resolution observations of tropospheric $\{\mathrm{H} 2 \mathrm{O}, \delta \mathrm{D}\}$ pairs - a review, Atmos. Meas. Tech., 9, 2845-2875, https://doi.org/10.5194/amt-9-2845-2016, 2016.

Seibert, P. and Frank, A.: Source-receptor matrix calculation with a Lagrangian particle dispersion model in backward mode, Atmos. Chem. Phys., 4, 51-63, https://doi.org/10.5194/acp-4-512004, 2004.

Shupe, M. D., Walden, V. P., Eloranta, E., Uttal, T., Campbell, J. R., Starkweather, S. M., and Shiobara, M.: Clouds at Arctic Atmospheric Observatories, Part I: Occurrence and Macrophysical Properties, J. Appl. Meteorol., 50, 626-644, https://doi.org/10.1175/2010jamc2467.1, 2010.

Simpson, W. R., Alvarez-Aviles, L., Douglas, T. A., Sturm, M., and Domine, F.: Halogens in the coastal snow pack near Barrow, Alaska: Evidence for active bromine air-snow chemistry during springtime, Geophys. Res. Lett., 32, L04811, https://doi.org/10.1029/2004GL021748, 2005.

Simpson, W. R., von Glasow, R., Riedel, K., Anderson, P., Ariya, P., Bottenheim, J., Burrows, J., Carpenter, L. J., Frieß, U., Goodsite, M. E., Heard, D., Hutterli, M., Jacobi, H. W., Kaleschke, L., Neff, B., Plane, J., Platt, U., Richter, A., Roscoe, H., Sander, R., Shepson, P., Sodeau, J., Steffen, A., Wagner, T., and Wolff, E.: Halogens and their role in polar boundary-layer ozone depletion, Atmos. Chem. Phys., 7, 4375-4418, https://doi.org/10.5194/acp7-4375-2007, 2007.

Simpson, W. R., Peterson, P. K., Frieß, U., Sihler, H., Lampel, J., Platt, U., Moore, C., Pratt, K., Shepson, P., Halfacre, J., and Nghiem, S. V.: Horizontal and vertical structure of reactive bromine events probed by bromine monoxide MAX-DOAS, Atmos. Chem. Phys., 17, 9291-9309, https://doi.org/10.5194/acp17-9291-2017, 2017.

Smith, J. A., Ackerman, A. S., Jensen, E. J., and Toon, O. B.: Role of deep convection in establishing the isotopic composition of water vapor in the tropical transition layer, Geophys. Res. Lett., 33, L06812, https://doi.org/10.1029/2005g1024078, 2006.

Steffen, A., Douglas, T., Amyot, M., Ariya, P., Aspmo, K., Berg, T., Bottenheim, J., Brooks, S., Cobbett, F., Dastoor, A., Dommergue, A., Ebinghaus, R., Ferrari, C., Gardfeldt, K., Goodsite, M. E., Lean, D., Poulain, A. J., Scherz, C., Skov, H., Sommar, J., and Temme, C.: A synthesis of atmospheric mercury depletion event chemistry in the atmosphere and snow, Atmos. Chem. Phys., 8, 1445-1482, https://doi.org/10.5194/acp-8-1445-2008, 2008.

Stewart, M. K.: Stable isotope fractionation due to evaporation and isotopic exchange of falling waterdrops: Applications to atmospheric processes and evaporation of lakes, J. Geophys. Res., 80, 1133-1146, 1975.
Stohl, A., Forster, C., Frank, A., Seibert, P., and Wotawa, G.: Technical note: The Lagrangian particle dispersion model FLEXPART version 6.2, Atmos. Chem. Phys., 5, 2461-2474, https://doi.org/10.5194/acp-5-2461-2005, 2005.

Stohl, A., Sodemann, H., Eckhardt, S., Frank, A., Seibert, P., and Wotawa, G.: The Lagrangian particle dispersion model FLEXPART version 8.2, FLEXPART user guide, 2011.

Stohl, A., Klimont, Z., Eckhardt, S., Kupiainen, K., Shevchenko, V. P., Kopeikin, V. M., and Novigatsky, A. N.: Black carbon in the Arctic: the underestimated role of gas flaring and residential combustion emissions, Atmos. Chem. Phys., 13, 8833-8855, https://doi.org/10.5194/acp-13-8833-2013, 2013.

Stroeve, J. C., Serreze, M. C., Holland, M. M., Kay, J. E., Malanik, J., and Barrett, A. P.: The Arctic's rapidly shrinking sea ice cover: a research synthesis, Climate Change, 110, 1005-1027, 2012.

Tarasick, D. W., Davies, J., Smit, H. G. J., and Oltmans, S. J.: A re-evaluated Canadian ozonesonde record: measurements of the vertical distribution of ozone over Canada from 1966 to 2013, Atmos. Meas. Tech., 9, 195-214, https://doi.org/10.5194/amt-9195-2016, 2016

Toyota, K., Dastoor, A. P., and Ryzhkov, A.: Air-snowpack exchange of bromine, ozone and mercury in the springtime Arctic simulated by the 1-D model PHANTAS - Part 2: Mercury and its speciation, Atmos. Chem. Phys., 14, 4135-4167, https://doi.org/10.5194/acp-14-4135-2014, 2014.

Tukey, J. W.: Exploratory Data Analysis, Addison-Wesley Pub. Co., Reading, 688 pp., 1977.

Wagner, T., Leue, C., Wenig, M., Pfeilsticker, K., and Platt, U.: Spatial and temporal distribution of enhanced boundary layer $\mathrm{BrO}$ concentrations measured by the GOME instrument aboard ERS-2, J. Geophys. Res., 106, 24225-24235, https://doi.org/10.1029/2000jd000201, 2001.

Warwick, N. J., Pyle, J. A., Carver, G. D., Yang, X., Savage, N. H., O'Connor, F. M., and Cox, R. A.: Global modeling of biogenic bromocarbons, J. Geophys. Res., 111, D24305, https://doi.org/10.1029/2006jd007264, 2006.

Weaver, D., Strong, K., Schneider, M., Rowe, P. M., Sioris, C., Walker, K. A., Mariani, Z., Uttal, T., McElroy, C. T., Vömel, H., Spassiani, A., and Drummond, J. R.: Intercomparison of atmospheric water vapour measurements at a Canadian High Arctic site, Atmos. Meas. Tech., 10, 2851-2880, https://doi.org/10.5194/amt-10-2851-2017, 2017.

WMO: International meteorological vocabulary, 2nd Edn., Secretariat of the World Meteorological Organization, Geneva, Switzerland, 1992.

Yang, X., Cox, R. A., Warwick, N. J., Pyle, J. A., Carver, G. D., O'Connor, F. M., and Savage, N. H.: Tropospheric bromine chemistry and its impacts on ozone: A model study, J. Geophys. Res., 110, D23311, https://doi.org/10.1029/2005jd006244, 2005.

Yang, X., Pyle, J. A., and Cox, R. A.: Sea salt aerosol production and bromine release: Role of snow on sea ice, Geophys. Res. Lett., 35, L16815, https://doi.org/10.1029/2008g1034536, 2008.

Yang, X., Pyle, J. A., Cox, R. A., Theys, N., and Van Roozendael, M.: Snow-sourced bromine and its implications for polar tropospheric ozone, Atmos. Chem. Phys., 10, 7763-7773, https://doi.org/10.5194/acp-10-7763-2010, 2010.

Yang, X., Abraham, N. L., Archibald, A. T., Braesicke, P., Keeble, J., Telford, P. J., Warwick, N. J., and Pyle, J. A.: How sensitive is the recovery of stratospheric ozone to changes in con- 
centrations of very short-lived bromocarbons?, Atmos. Chem. Phys., 14, 10431-10438, https://doi.org/10.5194/acp-14-104312014, 2014.

Zhao, X., Strong, K., Adams, C., Schofield, R., Yang, X., Richter, A., Friess, U., Blechschmidt, A. M., and Koo, J. H.: A case study of a transported bromine explosion event in the Canadian high arctic, J. Geophys. Res., 121, 457-477, 2016a.
Zhao, X., Fioletov, V., Cede, A., Davies, J., and Strong, K.: Accuracy, precision, and temperature dependence of Pandora total ozone measurements estimated from a comparison with the Brewer triad in Toronto, Atmos. Meas. Tech., 9, 5747-5761, https://doi.org/10.5194/amt-9-5747-2016, 2016 b. 